\title{
In vitro and in vivo efficacy of thiacloprid against Echinococcus multilocularis
}



\begin{abstract}
Background: Alveolar echinococcosis (AE) is a chronic zoonosis caused by the larval form of Echinococcus multilocularis (E. multilocularis). Current chemotherapy against AE has relied on albendazole and mebendazole, which only exhibit parasitostatic and not parasiticidal efficacy. Therefore, novel compounds for the treatment of this disease are needed.

Methods: Phosphoglucose isomerase (PGI) assays were used for compound screening of seven neonicotinoids. The anti-parasitic effects of thiacloprid were then evaluated on E. multilocularis metacestode vesicles, germinal cells and protoscoleces in vitro. Human foreskin fibroblasts (HFF) and Reuber rat hepatoma (RH) cells were used to assess cytotoxicity. Glucose consumption in E. multilocularis protoscoleces and germinal cells was assessed by measuring uptake of 2-deoxyglucose (2-DG). Molecular docking was used to evaluate the potential binding sites of thiacloprid to acetylcholine receptors. In vivo efficacy of thiacloprid was evaluated in mice by secondary infection with E. multilocularis. In addition, ELISA and flow cytometry were used to evaluate the effects of cytokines and T lymphocyte subsets after thiacloprid treatment. Furthermore, collagen deposition and degradation in the host lesion microenvironment were evaluated.
\end{abstract}

Results: We found that thiacloprid is the most promising compound, with an $I C_{50}$ of $4.54 \pm 1.10 \mu \mathrm{M}$ and $2.89 \pm 0.34 \mu \mathrm{M}$, respectively, against in vitro-cultured E. multilocularis metacestodes and germinal cells. Thiacloprid was less toxic for HFF and RH mammalian cell lines than for metacestodes. In addition, thiacloprid inhibited the acetylcholinesterase activity in protoscoleces, metacestodes and germinal cells. Thiacloprid inhibited glucose consumption by protoscoleces and germinal cells. Subsequently, transmission electron microscopy revealed that treatment with thiacloprid damaged the germinal layer. In vivo, metacestode weight was significantly reduced following oral administration of thiacloprid at 15 and $30 \mathrm{mg} / \mathrm{kg}$. The level of $\mathrm{CD} 4^{+} \mathrm{T}$ lymphocytes in metacestodes and spleen increased after thiacloprid treatment. Anti-echinococcosis-related cytokines (IL-2, IL-4, IL-10) were significantly increased. Furthermore, thiacloprid inhibited the expression of matrix metalloproteinases (MMPs 1, 3, 9, 13) and promoted collagen deposition in the host lesion microenvironment.

Conclusions: The results demonstrated that thiacloprid had parasiticidal activity against $E$. multilocularis in vitro and in vivo, and could be used as a novel lead compound for the treatment of AE.

Keywords: Echinococcus multilocularis, Thiacloprid, Neonicotinoids, Lymphocytes, Cytokines, Matrix metalloproteinases

*Correspondence: judyml-325@163.com; geriligao@hotmail.com ${ }^{1}$ Research Center for High Altitude Medicine, Qinghai University, Xining 810001, Qinghai, China

Full list of author information is available at the end of the article

\section{Background}

Alveolar echinococcosis (AE) is a rare zoonotic parasitic disease caused by the metacestode stage of Echinococcus multilocularis, which presents unclearly delimited foci (alveococcus) located in the liver (in 99\% of cases)

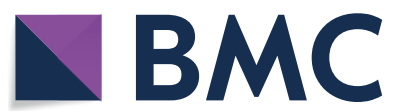

(c) The Author(s) 2021. Open Access This article is licensed under a Creative Commons Attribution 4.0 International License, which permits use, sharing, adaptation, distribution and reproduction in any medium or format, as long as you give appropriate credit to the original author(s) and the source, provide a link to the Creative Commons licence, and indicate if changes were made. The images or other third party material in this article are included in the article's Creative Commons licence, unless indicated otherwise in a credit line to the material. If material is not included in the article's Creative Commons licence and your intended use is not permitted by statutory regulation or exceeds the permitted use, you will need to obtain permission directly from the copyright holder. To view a copy of this licence, visit http://creativecommons.org/licenses/by/4.0/. The Creative Commons Public Domain Dedication waiver (http://creativeco mmons.org/publicdomain/zero/1.0/) applies to the data made available in this article, unless otherwise stated in a credit line to the data. 
[1]. The exogenous gemmation of $\mathrm{AE}$ can penetrate into the surrounding tissue; it presents tumor-like features and can form metastases in distant organs through the blood and lymphatic system. Incidence of E. multilocularis has so far been restricted to the Northern Hemisphere [1]. The life cycle of echinococcus involves two mammalian hosts, usually including a definitive host of canids or foxes and an intermediate host of small rodents [2]. Humans are aberrant hosts and become infected by orally ingesting $E$. multilocularis eggs from the environment. Oncospheres pass through the portal and reach the liver, where they usually settle and develop as larvae (metacestodes) [3]. The interaction between the parasite and the host leads to the formation of infectious granuloma reaction [4-6].

The ideal treatment for $\mathrm{AE}$ is still radical surgery, accompanied by chemotherapy. However, surgery is reserved for early-stage disease when lesions can be completely resected with a safe margin $(\geq 2 \mathrm{~cm})$ of unaffected tissue and no distant metastases [7]. Because most cases are found at an advanced stage, only $35 \%$ of patients can undergo curative surgery [7]. In inoperable cases, chemotherapy alone is applied. Systemic anti-infective treatment relies on continuous administration of two benzimidazole carbamates, albendazole (ABZ) and mebendazole (MBZ), which are the only anti-infective drugs clinically effective in interrupting larval growth of Echinococcus spp. $[8,9]$. Stem cells of E. multilocularis are more resistant to benzimidazoles than other cells of the parasite, and this, together with the limited uptake and half-life of benzimidazoles, leads to a parasitostatic rather than parasiticidal effect [10]. In addition, benzimidazoles are not always well tolerated and can cause serious side effects such as hepatotoxicity in some patients [11]. Thus, improved drug treatments are urgently needed.

Drugs currently on the market, or under development for other indications, are being explored to identify novel treatment options for AE. Repurposed drugs mainly include broad-spectrum anti-infective drugs, drugs that inhibit cellular proliferation (such as anti-cancer compounds), natural products, and substances that are active against other pathogens [12, 13]. Neonicotinoids are important insecticides that have been developed over the last three decades (Additional file 1: Figure S1). Neonicotinoids are recognized as systemic insecticides used to protect crops from penetrating insects and to control the body surface parasites of cats and dogs [14]. The insecticidal activity of neonicotinoids occurs largely through their excitatory effect on the nicotinic acetylcholine receptors (nAchRs) of the insect's postsynaptic membrane, thereby causing acetylcholine to accumulate and leading to insect paralysis and death [15]. Neonicotinoids are also effective acetylcholinesterase inhibitors [16]. Furthermore, their low affinity for several subsets of mammalian nAChRs in binding assays suggests that neonicotinoids are relatively safe for mammals including humans [17]. Unlike nicotine, neonicotinoids have low toxicity and pose little risk to mammals [18]. They cannot easily penetrate the blood-brain barrier [19] and fail to accumulate in animal tissues [20]. As reported by Schwabe et al., hydatid scoleces and brood capsules were found to contain special acetylcholinesterase [21]. Koziol et al. highlighted the lack of a cholinergic component in the protoscolex and cyst wall of E. multilocularis [22]. Anthelmintic drugs that are currently marketed act mainly on nematode nAchRs [23], but are ineffective against echinococcus.

The neonicotinoids against E. multilocularis metacestode vesicles were screened in vitro, and thiacloprid showed the effect against metacestodes (Additional file 2: Figure S2). In this study, we evaluated the in vitro anthelmintic effects of thiacloprid on metacestodes, germinal cells and protoscoleces of E. multilocularis. We further investigated the in vivo efficacy and cytotoxicity of thiacloprid in experimentally infected mice.

\section{Methods}

\section{Animals and ethics statement}

Specific pathogen-free (SPF) BALB/c mice (female, 18-20 g) and Mongolian gerbils (male, 60-80 g) were supplied by the Nanjing Qinglongshan animal breeding base. Animals were housed in temperature-controlled $\left(23 \pm 1{ }^{\circ} \mathrm{C}\right)$, light-cycled $(12 \mathrm{~h}$ light/dark cycle) individual ventilated cages. Food and water were provided ad libitum. All the operations were conducted under $0.3 \%$ pentobarbital sodium anesthesia, and all efforts were made to minimize the pain of animals. All animal experiments were performed in accordance with the regulations of the Ministry of Science and Technology of China and the administrative measures of experimental animals in Qinghai Province, which were approved by the Institutional Review Board of the Medical College of Qinghai University (IACUC-201905010005) and the Qinghai University Affiliated Hospital (AF-RHEC-0018-01).

\section{Cells and chemicals}

Human foreskin fibroblasts (HFF) and Reuber rat hepatoma (RH) cells were purchased from Procell (Wuhan, China). Dulbecco's modified Eagle medium (DMEM), Medium 199 and fetal bovine serum (FBS) were obtained from Gibco (Auckland, New Zealand). Solutions containing trypsin-EDTA, penicillin-streptomycin $(100 \times)$ and gentamicin were purchased from Procell. All chemicals were purchased from Sigma-Aldrich (St. Louis, MO, USA), unless stated otherwise. All 
neonicotinoids were prepared as $10 \mathrm{mM}$ stock solutions in dimethyl sulfoxide (DMSO) upon arrival and stored at $-20^{\circ} \mathrm{C}$.

\section{E. multilocularis metacestode in vitro cultivation}

Larval material (isolate Qinghai) was obtained from female $\mathrm{BALB} / \mathrm{c}$ mice experimentally infected with $E$. multilocularis homogenized larval tissue, which was originally isolated from a naturally infected plateau pika (Ochotona curzoniae) collected in Yushu, Qinghai province, China. Molecular identification of the isolate of $E$. multilocularis is described by Li et al. [24]. Echinococcus multilocularis metacestodes were prepared and cultured as described previously [25]. Briefly, E. multilocularis metacestode tissue material was retrieved from euthanized mice that had been intraperitoneally infected with E. multilocularis metacestodes for 3 months. The isolated metacestodes were crushed through a metal tea strainer, and incubated overnight in phosphate-buffered saline (PBS) containing 1\% penicillin/streptomycin. Then, $1 \mathrm{ml}$ metacestode tissue was co-cultured with $5 \times 10^{6}$ Reuber rat hepatoma $(\mathrm{RH})$ feeder cells in DMEM containing $10 \%$ FBS and $1 \%$ penicillin/streptomycin at $37{ }^{\circ} \mathrm{C}$ and $5 \% \mathrm{CO}_{2}$, with medium changes once a week. In vitro-cultured metacestode vesicles were used for experiments when they reached diameters of 2-4 mm [26]. Some of the vesicles were fixed with $4 \%$ paraformaldehyde for pathological examination.

\section{Confirmation of metacestode vesicles by RT-PCR}

Metacestode vesicles (without host cell contamination) were detected by reverse transcription polymerase chain reaction (RT-PCR). Total RNA was extracted from metacestode vesicles and host tissue (normal mouse liver) using the RNAsimple Total RNA Kit (TianGen Biotech, Beijing, China) according to the manufacturer's instructions. The first-strand cDNA was synthesized using the FastKing gDNA Dispelling RT SuperMix Kit (TianGen Biotech). PCR was performed using primers for the specific amplification of E. multilocularis GAPDH [27] and mouse GADPH (forward: 5'-CGTGGGGCAGCCCAG AACAT-3'; reverse: 5'-GAGCAATGCCAGCCCCAG CA-3').

The RT-PCR reaction was performed using the Mastercycler Nexus PCR apparatus in a final volume of $50 \mu \mathrm{l}$ : $25 \mu \mathrm{l} 2 \times$ Taq PCR Mastermix (TianGen Biotech), $1.2 \mu \mathrm{l}$ of each primer $(10 \mu \mathrm{M}), 2 \mu \mathrm{l}$ cDNA product, $20.6 \mu \mathrm{l}$ $\mathrm{ddH}_{2} \mathrm{O}$. Amplification was performed using the following conditions: $3 \mathrm{~min}$ at $94{ }^{\circ} \mathrm{C}$ followed by 30 cycles of 94 ${ }^{\circ} \mathrm{C}$ for $30 \mathrm{~s}, 60{ }^{\circ} \mathrm{C}$ for $30 \mathrm{~s}$ and $72{ }^{\circ} \mathrm{C}$ for $20 \mathrm{~s}$, and a final extension step at $72{ }^{\circ} \mathrm{C}$ for $3 \mathrm{~min}$. PCR products were separated by $2 \%$ agarose gel electrophoresis and stained with GeneRed (TianGen Biotech) for visualization under
UV light. Metacestode germinal cells were subsequently identified in the same manner.

\section{In vitro assessment of thiacloprid against $E$. multilocularis metacestodes}

The efficacy of thiacloprid against the E. multilocularis metacestode was evaluated by applying a phosphoglucose isomerase (PGI) assay that measures the release of the enzyme phosphoglucose isomerase upon physical impairment of metacestodes [26]. In brief, medium without phenol red (DMEM, 1\% penicillin/streptomycin sulfate, $2 \mathrm{mM} \mathrm{L}$-glutamine) was added to the same volume of vesicles and distributed to 48-well (12-15 per vesicles) plates. Subsequently, metacestodes were incubated for 5 days with different concentrations $(0,0.06,1.2,2.5,5$, $10,20,40,80$ and $160 \mu \mathrm{M})$ of thiacloprid or praziquantel (PZQ), after which PGI release was quantified exactly as described in Stadelmann et al. [28]. Triton X-100 (0.1\% in PBS) was applied as a positive control (maximal release of vesicle fluid). Each condition was tested in biological triplicate. After 5 days of incubation, $200 \mu \mathrm{l}$ medium supernatant was collected from each well and stored at $-20^{\circ} \mathrm{C}$ until further measurements were performed. PGI measurements were performed as described earlier [26], except that an Infinite M200 PRO reader (Tecan, Männedorf, Switzerland) was used to measure the increase in absorbance at $340 \mathrm{~nm}$. PGI activity was calculated using the $\mathrm{EC}_{50}$ calculator (https://www.aatbio.com/tools/ec50calculator) from the linear regression of the enzyme reaction over time and presented as a percentage relative to the values obtained by treatment of vesicles with $0.1 \%$ Triton X-100.

\section{Assessment of in vitro toxicity in human foreskin fibroblasts and Reuber rat hepatoma cells}

An alamarBlue assay was used to assess the toxicity of thiacloprid to confluent and pre-confluent mammalian cells in vitro [29]. Human foreskin fibroblasts (HFF, Procell) and rat hepatoma cells (RH, Procell) were seeded into 96-well cell culture plates in DMEM supplemented with $10 \%$ FBS and $1 \%$ penicillin-streptomycin at $37{ }^{\circ} \mathrm{C}$ and $5 \% \mathrm{CO}_{2}$. For detecting the growth inhibitory effects of confluent cells, HFF and RH cells were seeded at 10,000 cells per well and 50,000 cells per well, respectively. After overnight culture, thiacloprid or PZQ was added and diluted in serial concentrations $(0,0.6,1.2,2.5$, $5,10,20,40,80$ and $160 \mu \mathrm{M})$. For detecting growth inhibitory effects on proliferating cells, cells were seeded at 1000 (HFF) and 5000 (RH) cells per well. Thiacloprid was added after $5 \mathrm{~h}$ of cell attachment. To measure the viability of the cells after treatment for 5 days, the alamarBlue assay was employed and viability calculated as described previously [29]. 


\section{Assessment of in vitro toxicity in E. multilocularis germinal cells}

To evaluate the activity of thiacloprid against parasitic stem cells, germinal cells from in vitro metacestode vesicles were investigated as described by Spiliotis et al. [30]. Briefly, 20 units of cells were distributed into a black 384-well plate. Different concentrations of thiacloprid or PZQ $(0,0.06,1.2,2.5,5,10,20,40,80$ and $160 \mu \mathrm{M})$ were added to the cells. After culture at $37^{\circ} \mathrm{C}$ for 5 days under a humid nitrogen atmosphere, $25 \mu$ CellTiter-Glo containing $1 \%$ Triton X-100 was added. The plates were incubated at room temperature in the dark for $15 \mathrm{~min}$. After the total destruction of the cellular aggregates, luminescence was measured using an Infinite M200 PRO reader (Tecan), and $0 \mu \mathrm{M}$ values were set to $100 \%$ viability. The $\mathrm{IC}_{50}$ values were calculated using an online $\mathrm{IC}_{50}$ calculator after logit-log transformation. Four independent replicates were conducted.

\section{Preparation of $E$. multilocularis protoscoleces}

The protoscoleces were isolated from metacestodes in Mongolian gerbils (Additional file 3: Figure S3). Metacestodes were removed aseptically from the abdominal cavities of Mongolian gerbils in a biosafety cabinet after euthanasia. The metacestodes were sliced in $1 \times$ PBS and filtered through four layers of sterile gauze into a $50-\mathrm{ml}$ sterile centrifuge tube. The protoscoleces were first filtered by a $100-\mu \mathrm{m}$ cell strainer, and then the calcified bodies were removed with a $40-\mu \mathrm{m}$ cell strainer. The protoscoleces naturally settled and were washed with PBS 8-10 times as backup.

\section{Efficacy of thiacloprid against E. multilocularis protoscoleces in vitro}

Viable protoscoleces were cultured in Medium 199, supplemented with $1 \%$ penicillin-streptomycin, $50 \mu \mathrm{g} / \mathrm{ml}$ gentamicin and $4 \mathrm{mg} / \mathrm{ml}$ glucose according to a previously described method [31]. Protoscoleces were added into six-well cell culture plates and incubated for 5 days with thiacloprid $(0,0.06,1.2,2.5,5,10,20,40$ and $80 \mu \mathrm{M})$. PZQ was used as a positive control. The protoscoleces were cultured in an incubator at $37{ }^{\circ} \mathrm{C}$ and $5 \% \mathrm{CO}_{2}$ for 7 days. Additionally, $0.1 \%$ eosin exclusion test was used to evaluate the viability of protoscoleces. To reduce the bias as much as possible, protoscolex viability was observed by two experimenters under double-blind conditions. Each experiment was conducted three times.

Determination of cholinesterase activity in E. multilocularis protoscoleces, metacestodes and germinal cells

The effects of thiacloprid on the acetylcholinesterase activity of E. multilocularis protoscoleces, metacestodes and germinal cells were determined according to a previously described method [32, 33]. The protoscoleces, metacestode and germinal cells were washed twice with PBS and homogenized with an electric homogenizer in precooled PBS. Centrifugation of the homogenates was performed at $100,000 \times g$ for $30 \mathrm{~min}$. The protein concentration of the supernatant was determined by the modified Lowry method according to the instructions, and the concentration was adjusted to $2 \mathrm{mg} / \mathrm{ml}$. Thiacloprid $(5 \mu \mathrm{M})$ was added to the extract and incubated at $37{ }^{\circ} \mathrm{C}$ for $10 \mathrm{~min}$. The extract was supplemented with $0.1 \%$ DMSO as control. Subsequently, acetylcholinesterase activity was assessed according to Ellman's procedure [33] using a microplate with $260 \mu$ of $0.1 \mathrm{M}$ PBS buffer $\mathrm{pH} 8.0,10 \mu \mathrm{l}$ of $10 \mathrm{mM}$ dithiobisnitrobenzoic acid solution, $2.5 \mu \mathrm{l}$ of $75 \mathrm{mM}$ substrate (acetylthiocholine iodide) and $25 \mu \mathrm{l}$ of the sample treated with thiacloprid. The OD increment was measured at $412 \mathrm{~nm}$ using an Infinite M200 PRO reader (Tecan). Each experiment was conducted three times. BW284c51 (CAS number: 402-40-4, Sigma) was used as a positive control.

\section{Glucose consumption}

Glucose consumption in E. multilocularis protoscoleces and germinal cells was detected using the Screen Quest Colorimetric Glucose Uptake Assay Kit (AAT Bioquest, Sunnyvale, CA, USA). The newly separated protoscoleces were washed twice with Krebs-ringer phosphate HEPES (KRPH) buffer and then resuspended in $1 \mathrm{ml}$ glucose uptake buffer for $1 \mathrm{~h}$. Each well contained about 200 protoscoleces. Isolated E. multilocularis germinal cells were resuspended with serum-free DMEM and cultured overnight in nitrogen at $37^{\circ} \mathrm{C}$. Germinal cells were then washed twice with KPRH buffer and resuspended in $90 \mu \mathrm{l}$ glucose uptake buffer for $1 \mathrm{~h}$. Subsequently, the protoscoleces and germinal cells were added with $10 \mu \mathrm{l}$ thiacloprid $(5 \mu \mathrm{M})$ for $1 \mathrm{~h}$, and treated with $10 \mu \mathrm{l}$ 2-deoxyglucose (2DG) for $1 \mathrm{~h}$. The germinating cells treated with thiacloprid were labeled with mitochondria red fluorescent probe (Beyotime, Shanghai, China) and the percentage of living cells was measured by flow cytometry. The protoscoleces and germinal cells were washed twice with KRPH buffer and then lysed with $25 \mu$ l acidic lysis buffer in an Eppendorf tube (EP) for $30 \mathrm{~min}$. A neutralizing buffer was added to each well and left at room temperature for $20 \mathrm{~min}$ to neutralize the lysate. Fifty microliters of 2DG uptake assay working solution was added to each tube and incubated at room temperature for $2 \mathrm{~h}$. Lastly, the mixture was transferred to a 96-well cell culture plate and the absorbance was measured at $570 \mathrm{~nm}$ using an Infinite M200 PRO reader (Tecan). Albendazole sulfoxide (ABZSO, $15 \mu \mathrm{M})$ was used as a positive control [34]. Results are presented as a percentage relative to the values obtained without treatment. 


\section{Toxicity of thiacloprid in vivo}

Based on the previous thiacloprid dose concentration, we selected $15 \mathrm{mg} / \mathrm{kg}$ and $30 \mathrm{mg} / \mathrm{kg}$ thiacloprid concentrations to evaluate the toxicity in vivo [35]. The toxicity of thiacloprid was assessed in normal BALB/c mice. Normal mice were randomly divided into three groups and received the following treatments (6 animals per group): The control group was not administered any drug; the Thia15 group and Thia30 group received thiacloprid orally $(15 \mathrm{mg} / \mathrm{kg} /$ day and $30 \mathrm{mg} / \mathrm{kg} /$ day $)$. After 6 weeks of treatment, blood samples were collected from the orbital sinus of mice under anesthesia before euthanasia, which were preserved in EDTA-K2 anticoagulant tubes for white blood cell (WBC), hemoglobin ( $\mathrm{Hb}$ ) and platelet (PLT) analysis. For assessing biochemical indicators, blood samples were incubated in anticoagulant-free tubes at $37^{\circ} \mathrm{C}$ for $1 \mathrm{~h}$, followed by $3500 \mathrm{rpm}$ centrifugation for $10 \mathrm{~min}$. The isolated serum samples were used to detect relative levels of alanine aminotransferase (ALT), aspartate aminotransferase (AST), total bilirubin (TBIL), direct bilirubin (DBIL), indirect bilirubin (IBIL), total protein (TP), albumin (ALB), alkaline phosphatase (ALP), creatinine (CREA) and blood urea nitrogen (BUN). Subsequently, mice were sacrificed for harvesting the liver and kidneys, which were fixed in $4 \%$ paraformaldehyde, prepared for hematoxylin-eosin (HE) staining and observed under a Zeiss Vert.A1 microscope.

\section{In vivo effect of thiacloprid treatment in mice experimentally infected with E. multilocularis metacestodes}

In vitro-grown metacestode vesicles were pressed through a $500 \mu \mathrm{m}$ mesh and washed three times with sterile PBS. The parasite tissue was then taken up in an equal volume of sterile PBS. Each mouse was intraperitoneally injected with $200 \mu$ l suspension. Seven mice were injected with $200 \mu \mathrm{l}$ PBS as the control group. Twentyeight infected mice were randomly distributed into four groups (7 mice/group): the untreated group was not administered any drug; the $\mathrm{ABZ}$ group was treated with ABZ orally $(100 \mathrm{mg} / \mathrm{kg} /$ day $)$; and the Thia 15 group and Thia30 group received thiacloprid orally $(15 \mathrm{mg} / \mathrm{kg} /$ day and $30 \mathrm{mg} / \mathrm{kg} /$ day). Treatments of mice started 2 weeks post-infection, and treatments were administered daily for 6 weeks. After 6 weeks of treatment, whole blood via the orbital sinus was collected from mice and the animals were euthanized by $\mathrm{CO}_{2}$. Blood samples were incubated at $37^{\circ} \mathrm{C}$ for $1 \mathrm{~h}$ and centrifuged at $3500 \mathrm{rpm}$ for $10 \mathrm{~min}$ at $4{ }^{\circ} \mathrm{C}$. The serum was harvested and stored at $-20{ }^{\circ} \mathrm{C}$ for IL-2, IL-4, IL-10 and IgE detection. All metacestode tissues were collected, and the total wet weight of metacestodes per mice was determined. Furthermore, the content of cytokines in microcyst fluid was detected by enzyme-linked immunosorbent assay (ELISA). Several metacestode tissue specimens were processed for transmission electron microscopy (TEM) and histopathological experiments.

\section{Hematoxylin-eosin (HE) staining}

Tissues from experimental animals were washed in PBS and fixed in $4 \%$ paraformaldehyde at room temperature for $36 \mathrm{~h}$. On the next day, they were dehydrated, embedded, and sliced into 5- $\mu \mathrm{m}$ sections. After dewaxing and dehydrating, sections were stained with hematoxylin for 2-5 min, and re-stained with eosin for $15 \mathrm{~s}$. They were sealed with neutral gum and observed under a BX51 microscope (Olympus, Tokyo, Japan).

\section{Periodic acid Schiff (PAS) staining}

A Periodic Acid Schiff Stain Kit (Solarbio, Beijing, China) was used to show the PAS-positive laminated layer characteristic of E. multilocularis metacestodes. The section $(5 \mu \mathrm{m})$ was dewaxed in xylene and rehydrated in $100 \%, 95 \%, 80 \%$, and $75 \%$ alcohol baths. Staining was then carried out according to the kit instructions.

\section{Sirius red staining analysis}

The metacestodes were fixed with $4 \%$ paraformaldehyde and embedded in paraffin to make sections with a thickness of $5 \mu \mathrm{M}$. The sections were dewaxed with water, stained with Picrosirius red for $10 \mathrm{~min}$, rinsed and dehydrated with anhydrous ethanol, and sealed with neutral balsam after the xylene was transparent. Each section of $400 \times$ visual field image was randomly collected. The ratio of the area of all images collected to the area of the visual field was measured using the ImageJ analysis system, and the percentage of collagen fibre was calculated.

\section{T lymphocyte subset analysis}

The spleens of mice were removed and then weighed to calculate the spleen index. The spleen tissue was cut, softly pressed and dispersed by passing through $70-\mu \mathrm{m}$ cell strainers. Metacestode tissues were cut into pieces and then digested by $0.2 \%$ collagenase II to generate a single-cell suspension. The lymphocytes were separated based on gradient centrifugation with a lymphocyte separation kit (Tbdscience, Tianjin, China). The lymphocytes were incubated with FITC-conjugated anti-CD3 (BioLegend, San Diego, CA, USA), PE-conjugated anti-CD4 (BioLegend), and APC-conjugated anti-CD8 (BioLegend) antibodies, and then analyzed by flow cytometry using a NovoCyte flow cytometer (ACEA/Agilent, Santa Clara, CA, USA). 


\section{Enzyme-linked immunosorbent assay (ELISA)}

ELISA was employed to detect serum IL-2, IL-4, IL-10 and IgE following the manufacturer's instructions. Mouse collagen I and collagen III ELISA kits were used to measure the levels of collagen I and collagen III in the cell culture supernatant after intervention with thiacloprid. All ELISA kits were provided by Elabscience Biotechnology Co., Ltd., Wuhan, China. The OD value at $450 \mathrm{~nm}$ was read with a Tecan Infinite M200 PRO enzyme reader (Männedorf, Switzerland), and the concentration was calculated according to the standard curve.

\section{Scanning electron microscopy (SEM) and transmission electron microscopy (TEM)}

The variations in the microstructure of the protoscoleces or metacestodes were observed under an electron microscope [28]. In vitro-cultured E. multilocularis protoscoleces and metacestodes were treated with thiacloprid at 0 and $5 \mu \mathrm{M}$ for 5 days at $37{ }^{\circ} \mathrm{C}$ and $5 \% \mathrm{CO}_{2}$. They were washed twice in PBS and then fixed for $3 \mathrm{~h}$ with $2.5 \%$ glutaraldehyde $(\mathrm{pH}=7.2)$; next, they underwent $2 \mathrm{~h}$ post-fixation in $2 \% \mathrm{OsO}_{4}$ (SPI-CHEM, West Chester, PA, USA). Subsequently, the samples were washed in doubledistilled water and treated with $1 \%$ uranyl acetate for $25 \mathrm{~min}$. After the samples were washed again in doubledistilled water, dehydration was conducted in ethanol at continuous gradients (30-50-70-80-90-95-100\%) over a period of $10 \mathrm{~min}$. For SEM analysis, the dehydrated samples were dipped into hexamethyldisiloxane and then air-dried in a fume hood. The sample was observed under a Hitachi SU8100 scanning electron microscope (Tokyo, Japan) after gold spraying. For TEM analysis, the dehydrated samples passed through a dehydrating agent, and an epoxy resin (SPI-CHEM) permeated and polymerized at $60{ }^{\circ} \mathrm{C}$ overnight. A $50-\mathrm{nm}$ ultra-thin section was prepared and then loaded on a 300-mesh copper grid. It was stained with uranyl acetate and lead citrate (SPI-CHEM). The sample was observed under a Hitachi HT7700 transmission electron microscope. To reduce the bias, electron microscopy was observed by professionals in the case of an unknown group.

\section{Real-time qPCR}

Total RNA was extracted with TRIzol Reagent (Thermo Fisher Scientific, Waltham, MA, USA) according to the manufacturer's instructions. The purity and concentrations of RNA were quantified using NanoDrop 2000 absorbance measurements at 260/280 nm. Total RNA was converted into cDNA sequences using the FastKing gDNA Dispelling RT SuperMix Kit (TIANGEN Biotech), and RT-qPCR was performed using the RealUniversal Color PreMix Kit (TIANGEN Biotech) on an ABI QuantStudio 5 system (Applied Biosystems, Waltham,
MA, USA). The specific primers are shown in Additional file 4: Table S1. The PCR cycling conditions were as follows: pre-denaturation at $95^{\circ} \mathrm{C}$ for $15 \mathrm{~min}$ followed by 40 cycles at $95{ }^{\circ} \mathrm{C}$ for $10 \mathrm{~s}$ and $60{ }^{\circ} \mathrm{C}$ for $34 \mathrm{~s}$. The relative mRNA expression levels were quantified using the $2^{-}$ $\Delta \triangle \mathrm{CT}$ method. RPS18 served as an internal control.

\section{Western blotting analysis}

A total protein extraction kit (Solarbio) was used to extract cell or tissue total protein. The protein concentration was determined by the protein quantitative assay kit (Thermo Fisher Scientific). Then, electrophoresis was performed with $20-50 \mu \mathrm{g}$ of protein sample. The protein was separated by sodium dodecyl sulfate polyacrylamide gel electrophoresis (SDS-PAGE) and transferred to a $0.22 \mu \mathrm{m}$ PVDF membrane (Merck Millipore, Darmstadt, Germany). The PVDF membrane was blocked with $5 \%$ of nonfat powdered milk in Tris-buffered saline Tween 20 (TBST) for $1 \mathrm{~h}$ at room temperature. The membrane incubation with primary antibodies was performed at $4{ }^{\circ} \mathrm{C}$ overnight. The antibody information is listed in Additional file 5: Table S2. The membrane was washed with TBST and incubated with HRP-labeled secondary antibodies (1:5000, Abclonal, Wuhan, China) for $1 \mathrm{~h}$ at room temperature. Blotted membranes were visualized using enhanced chemiluminescence reagents (Thermo Fisher Scientific). Protein expression was depicted as the intensity of each protein relative to that of $\beta$-actin using ImageJ software.

\section{Statistical analysis}

The data are presented as the mean \pm standard deviation (SD) and were plotted with GraphPad Prism 8.0 software. The data for both groups were analyzed using unpaired two-samples $t$-tests. Multiple comparisons between more than two groups were analyzed using by one-way analysis of variance (ANOVA) or Kruskal-Wallis test (non-parametric), and $\mathrm{IC}_{50}$ and $\mathrm{EC}_{50}$ values were calculated using an online half-max graphing calculator (https://www.aatbio.com/index.html). Values of $P<0.05$ were considered statistically significant.

\section{Results}

In vitro activity of thiacloprid against $E$. multilocularis metacestodes

We successfully cultured E. multilocularis metacestode vesicles in vitro (Additional file 4: Figure S4). In the RT-PCR analysis, there was no amplification of mouse GAPDH in metacestode vesicles and germinal cells, thus confirming the absence of host cells, while the E. multilocularis GAPDH specific gene was amplified from metacestode esicles and germinal cells (Fig. 1a). Metacestode vesicles showed obvious germinal layer by $\mathrm{HE}$ staining 


\section{(See figure on next page.)}

Fig. 1 Thiacloprid against E. multilocularis metacestodes. a Identification of metacestode and germinal cell. Echinococcus multilocularis GAPDH and mice GAPDH were used for the characterization of E. multilocularis metacestodes and germinal cells (without host cell contamination). Lanes 1 and 5: metacestode; lanes 2 and 6: germinal cells; lanes 3 and 7: mouse liver; lanes 4 and 8: negative control. b Pathological observation of metacestode. Obvious germinal layer and laminated layer were observed in the metacestode section after HE staining. Scale bar $=50 \mu \mathrm{m}$. c Metacestode sections were stained with PAS. PAS stain presented a strongly PAS-positive basophilic laminated layer. Scale bar $=50 \mu \mathrm{m}$. $\mathbf{d}$ Different concentrations of thiacloprid or PZQ against E. multilocularis metacestodes. The thiacloprid or PZQ were tested by PGI assay on E. multilocularis metacestodes in a concentration series ranging from 0.6 to $160 \mu \mathrm{M}$ in triplicates. Treatment with $0.1 \%$ Triton X-100 served as a positive control and was set as $100 \%$. The data are presented as the mean \pm SD. e Metacestode vesicle morphology after thiacloprid or PZQ treatment. Metacestode vesicles collapsed after $5 \mu \mathrm{M}$ thiacloprid or PZQ treatment. f SEM of E. multilocularis metacestodes incubated in vitro with thiacloprid or PZQ. GL: germinal layer

(Fig. 1b). PAS staining showed positive laminated layer (Fig. 1c).

Seven neonicotinoids were initially screened in vitro on E. multilocularis metacestode vesicles at $20 \mu \mathrm{M}$. Only thiacloprid showed activity at 5 days and 12 days after PGI assay screening (Additional file 2: Figure S2). Subsequently, the metacestode vesicles were then treated with thiacloprid or PZQ at a series of concentrations (Fig. 1d). The $\mathrm{EC}_{50}$ of PZQ against $E$. multilocularis metacestode was $7.41 \pm 2.09 \mu \mathrm{M}$ by the PGI assay. Thiacloprid showed significant anti-metacestode activity. The $\mathrm{EC}_{50}$ value was determined to be $4.54 \pm 1.10 \mu \mathrm{M}$ by the PGI assay. Morphological alterations of metacestode vesicles resulted from thiacloprid were observed under a light microscope (Fig. 1e). After 5 days of treatment with $5 \mu \mathrm{M}$ thiacloprid, the vesicles exhibited contraction and collapse. The in vitro effect of thiacloprid was further confirmed by SEM (Fig. 1f). The E. multilocularis metacestode vesicles in the untreated group showed a typical intact structure: tegument was tightly attached to the germinal layer. Metacestode incubated with $5 \mu \mathrm{M}$ thiacloprid or PZQ for 5 days showed noticeable damage: only residual cellular material was observed in many parts of germinal layer tissue.

\section{Cytotoxicity measurements of thiacloprid on HFF and RH cells}

Cytotoxicity was assessed by Alamar Blue assay for thiacloprid or PZQ using confluent and pre-confluent cultures of HFF and $\mathrm{RH}$ cells (Fig. 2a, b). The $\mathrm{IC}_{50}$ values of thiacloprid on confluent and pre-confluent HFF were $68.73 \pm 9.71 \mu \mathrm{M}$ and $64.84 \pm 5.79 \mu \mathrm{M}$, respectively, while the $\mathrm{IC}_{50}$ values for confluent and pre-confluent $\mathrm{RH}$ cells were $91.36 \pm 1.33 \mu \mathrm{M}$ and $74.34 \pm 10.85 \mu \mathrm{M}$, respectively. The $\mathrm{IC}_{50}$ values of PZQ on confluent and pre-confluent HFF were $53.21 \pm 11.05 \mu \mathrm{M}$ and $6.71 \pm 1.88 \mu \mathrm{M}$, respectively (Fig. 2c). The $\mathrm{IC}_{50}$ values of $\mathrm{PZQ}$ on confluent and pre-confluent $\mathrm{RH}$ cells were $25.29 \pm 6.32 \mu \mathrm{M}$ and $11.63 \pm 3.52 \mu \mathrm{M}$, respectively (Fig. $2 \mathrm{~d}$ ). Thiacloprid or PZQ was less toxic to HFF and RH cells than to E. multilocularis metacestodes.

\section{Effect of thiacloprid on the viability of E. multilocularis germinal cells}

Germinal cells were isolated by trypsin digestion from in vitro-cultured metacestode vesicles (Additional file 6: Figure S4). The CellTiter-Glo assay was used to determine the effect of thiacloprid or PZQ on the germinal cells. The $\mathrm{IC}_{50}$ of PZQ against germinal layer cells was $2.59 \pm 0.33 \mu \mathrm{M}$ (Fig. 2e). Thiacloprid significantly inhibited germinal cell viability (Fig. 2f). More than $10 \mu \mathrm{M}$ of thiacloprid resulted in a significant reduction of viable cells with an inhibition rate of more than $80 \%$. At 2.5 and $5 \mu \mathrm{M}$, the cell viability rates of thiacloprid on germinal cells were $58.29 \pm 6.09 \%$ and $38.27 \pm 4.47 \%$, respectively. The $\mathrm{IC}_{50}$ of thiacloprid against germinal cells was $2.89 \pm 0.34 \mu \mathrm{M}$.

\section{Transmission electron microscopy visualization of the effects of thiacloprid treatment in E. multilocularis metacestodes}

Based on the determination of the anti-metacestode effect of thiacloprid, the ultrastructural effect of thiacloprid against $E$. multilocularis metacestode was further confirmed by TEM. Untreated E. multilocularis metacestode vesicles have typical morphological characteristics (Fig. 3a, b): the outer of the parasite tissue is composed of laminated layers, which are rich in carbohydrates and separate the parasitic tissue from the surrounding host tissue; the inner surface of the laminated layer is the tegument with numerous microtriches protruding into the laminated layer. The germinal layer, which adheres to the capsule, contains a variety of cell types, including muscle cells, subtegumentary cytons, connective tissue, and undifferentiated stem cells. After $5 \mu \mathrm{M}$ thiacloprid treatment, obvious ultrastructural damage was observed. The microtriches fell off obviously and the tegument became loose (Fig. 3c). The germinal layer structure was obviously destroyed and the cell structure was disordered (Fig. 3d). Part of the metacestode vesicle has observed germinal layer and tegument separation (Fig. 3e). 

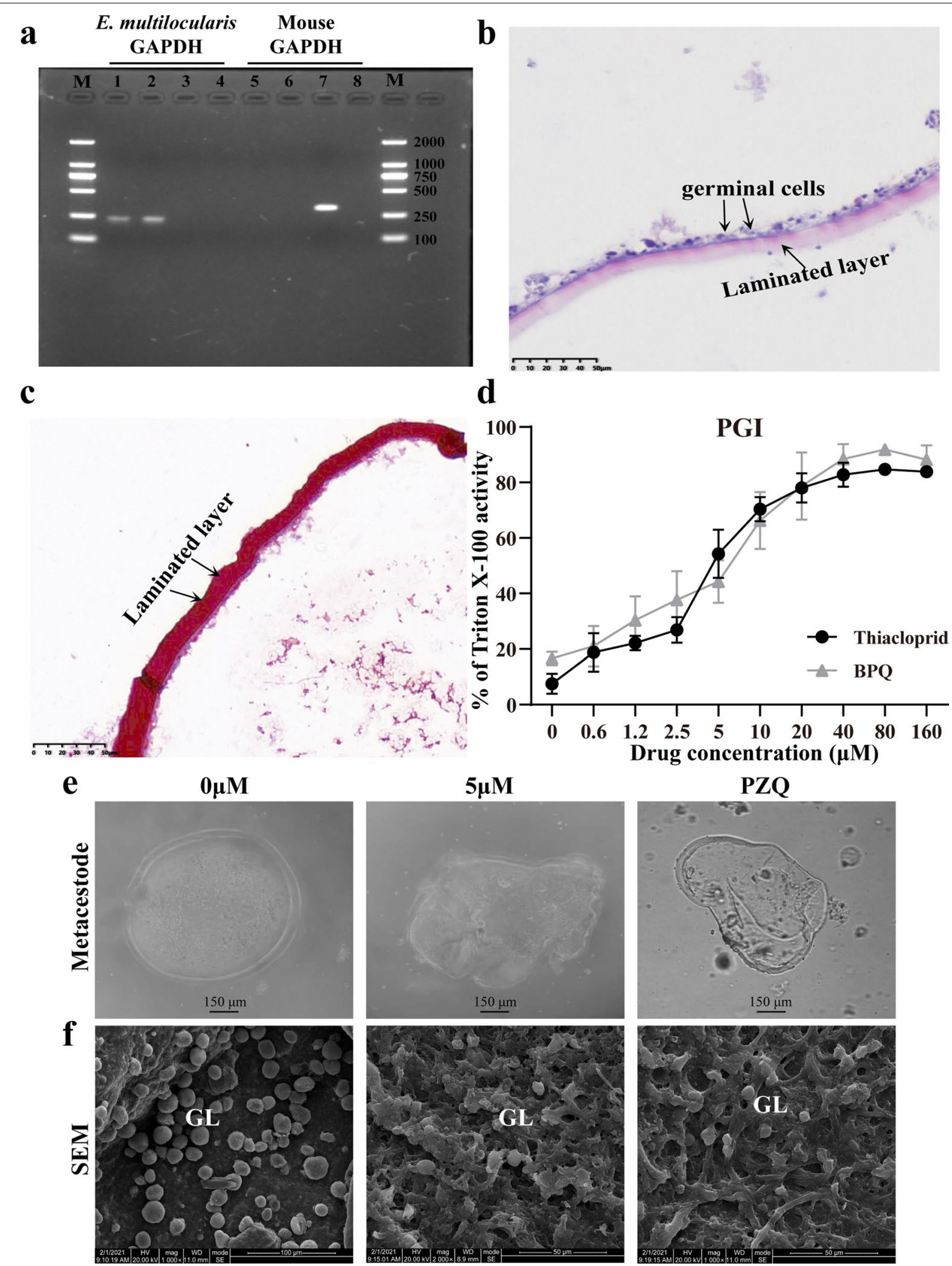

Fig. 1 (See legend on previous page.) 

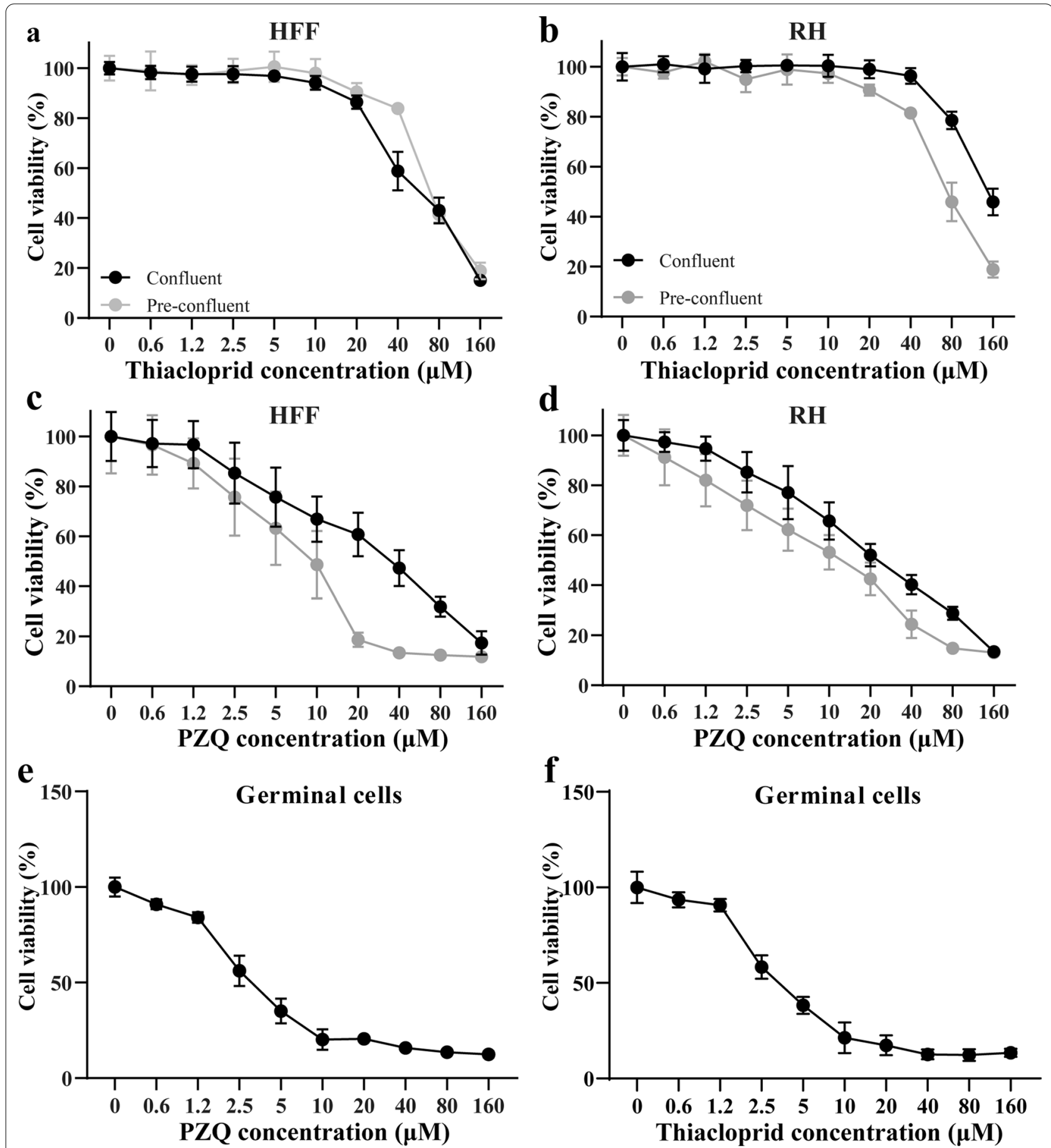

Fig. 2 Cytotoxicity of thiacloprid or PZQ on mammalian cells. Viability measurements on HFF and RH cells employed alamarBlue assay, while for $E$. multilocularis germinal cells viability was assessed by CellTiter-Glo assay. The data are presented as mean \pm SD obtained from three independent experiments. $\mathbf{a}$, $\mathbf{b}$ In vitro activity of thiacloprid against HFF and RH cells. c, $\mathbf{d}$ In vitro activity of PZQ against HFF and RH cells. e Cytotoxicity of thiacloprid on E. multilocularis germinal cells. $\mathbf{f}$ Cytotoxicity of $\mathrm{PZQ}$ on E. multilocularis germinal cells

In vitro activity of thiacloprid against $E$. multilocularis protoscoleces

After thiacloprid treatment at $5 \mu \mathrm{M}$ for 4 days,
$47.33 \pm 4.04 \%$ of protoscoleces were dead, while there was no significant effect on their viability after $1.2 \mu \mathrm{M}$ thiacloprid treatment (Fig. 4a). The dead protoscoleces 

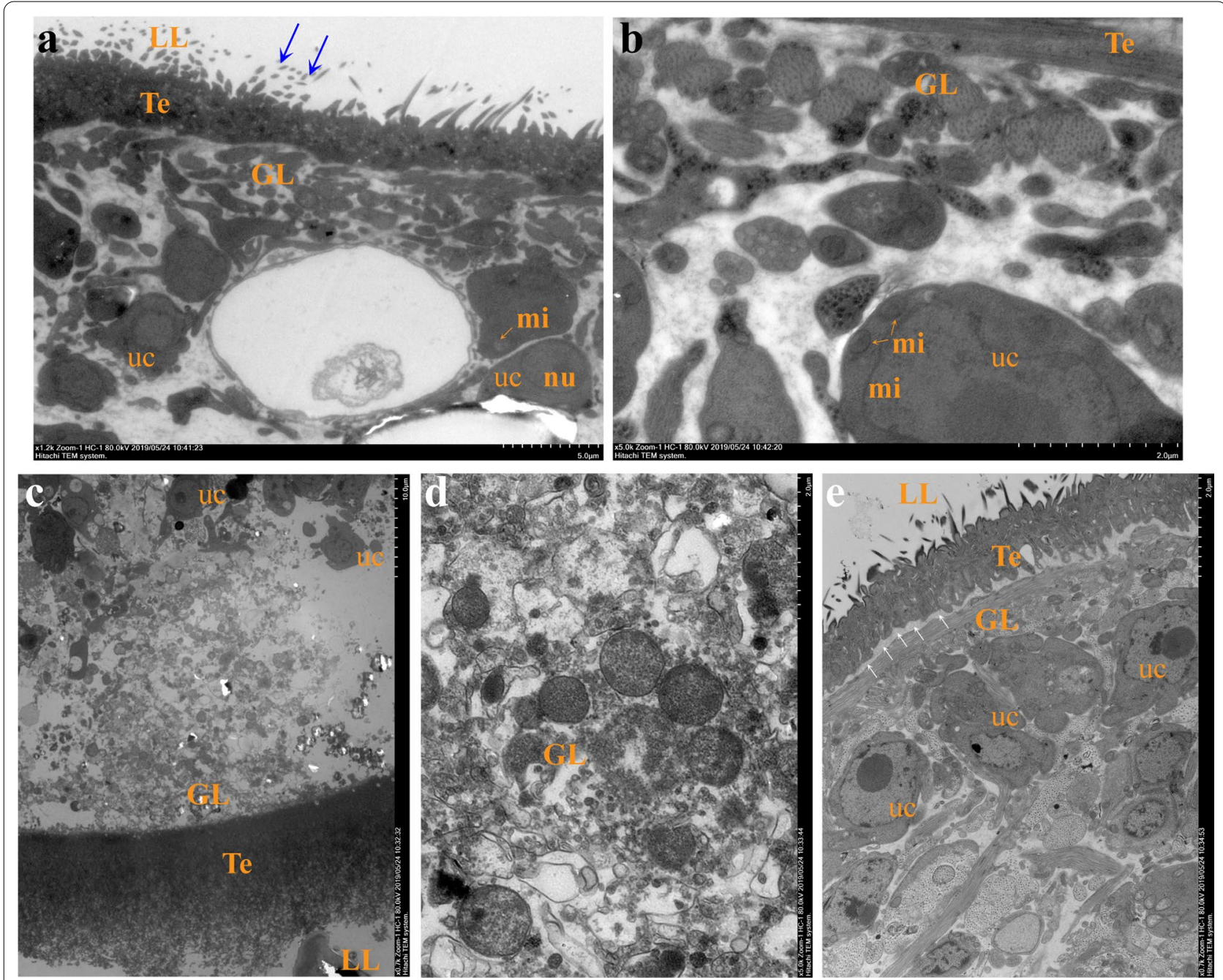

Fig. 3 Transmission electron microscopy of E. multilocularis metacestodes exposed to $5 \mu \mathrm{M}$ thiacloprid for 5 days. $\mathbf{a}$, $\mathbf{b}$ The normal metacestode structure. LL: laminated layer; Te: tegument; GL: germinal layer; uc: stem cell with large nucleus and nucleolus; mi: mitochondria. The blue arrows show microtriches. Scale bars in (a) and (b) are $5 \mu \mathrm{m}$ and $2 \mu \mathrm{m}$, respectively. c, d The germinal layer structural damage. Scale bars in (c) and (d) are $10 \mu \mathrm{m}$ and $2 \mu \mathrm{m}$, respectively. e The germinal layer was separated from the tegument (white arrow). Scale bar $=2 \mu \mathrm{m}$

were distinguished from the viable protoscoleces by eosin exclusion and observed under a light microscope (Fig. 4b). Furthermore, ultrastructural damage was revealed by SEM in the protoscoleces treated with thiacloprid at $5 \mu \mathrm{M}$ for 4 days compared with the protoscoleces without treatment (Fig. 4c). There was no significant change in the untreated protoscoleces. In contrast, after thiacloprid treatment, the surface of the protoscoleces was significantly contracted, and no obvious microvilli were observed. The positive control

(See figure on next page.)

Fig. 4 Thiacloprid against E. multilocularis protoscoleces and inhibited acetylcholinesterase activity. a Survival of protoscoleces after treatment with thiacloprid. The protoscoleces were exposed to thiacloprid for 7 days. To evaluate the survival of protoscoleces, a $0.1 \%$ eosin staining exclusion method was used daily. The positive control was $5 \mu \mathrm{M}$ PZQ. The data are presented as mean \pm SD obtained from three independent experiments. $\mathbf{b}$ Morphologies of protoscoleces after treatment with thiacloprid. After treatment with $5 \mu \mathrm{M}$ thiacloprid for 4 days, eosin staining was used to observe the protoscoleces. The red arrow shows the dead protoscoleces and the black arrow shows the live protoscoleces. Scale bar $=200 \mu \mathrm{m}$. c SEM of E. multilocularis protoscoleces incubated in vitro with $5 \mu \mathrm{M}$ thiacloprid for 4 days. $\mathbf{d}$ Thiacloprid inhibited acetylcholinesterase activity. BW284c51 was used as the positive control. The data are presented as mean \pm SD obtained from five independent experiments. e Thiacloprid inhibits glucose consumption. The protoscoleces or germinal cells were treated with $5 \mu \mathrm{M}$ thiacloprid, and relative glucose utilization was determined. The data are presented as mean \pm SD obtained from three independent experiments. ${ }^{*} P<0.05$ and ${ }^{* *} P<0.01$ 


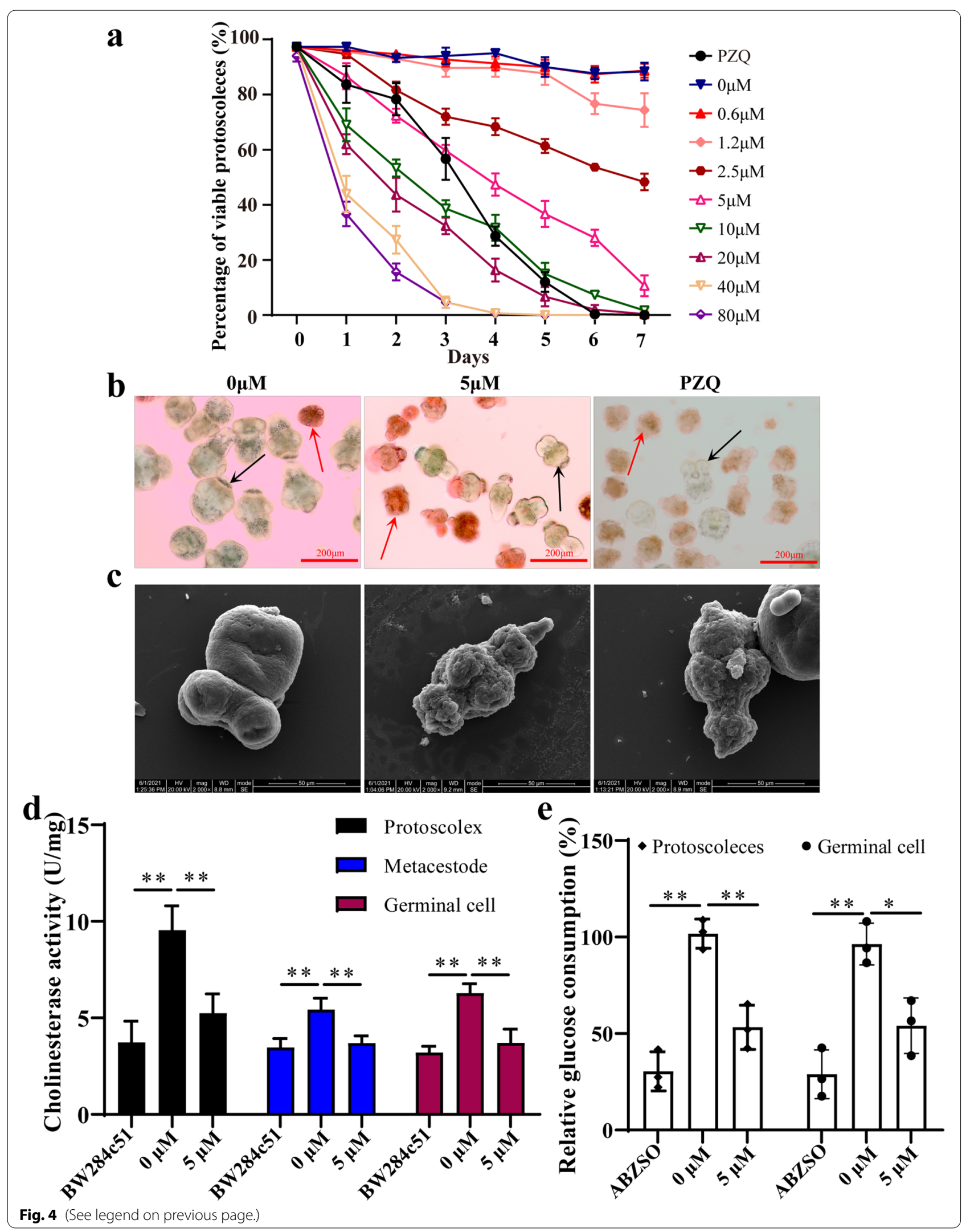


Table 1 Serum biochemical findings and blood cell analysis in BALB/c mice treated with thiacloprid for 6 weeks $(n=6)$

\begin{tabular}{llll}
\hline Balb/c mice & Control & Thia 15 & Thia 30 \\
\hline Alanine aminotransferase $(\mathrm{U} / \mathrm{L})$ & $65.67 \pm 6.53$ & $66.00 \pm 5.33$ & $67.50 \pm 5.01$ \\
Aspartate aminotransferase $(\mathrm{U} / \mathrm{L})$ & $198.20 \pm 28.15$ & $164.70 \pm 36.71$ & $180.50 \pm 45.71$ \\
Alkaline phosphatase $(\mathrm{U} / \mathrm{L})$ & $84.33 \pm 4.46$ & $57.67 \pm 5.43^{*}$ & $58.50 \pm 7.82^{*}$ \\
Total protein $(\mathrm{g} / \mathrm{L})$ & $63.30 \pm 2.41$ & $65.90 \pm 4.76$ & $65.82 \pm 4.39$ \\
Globulin $(\mathrm{g} / \mathrm{L})$ & $34.80 \pm 2.83$ & $36.67 \pm 4.71$ & $37.77 \pm 4.81$ \\
Albumin $(\mathrm{g} / \mathrm{L})$ & $28.50 \pm 1.57$ & $28.95 \pm 2.35$ & $29.72 \pm 1.49$ \\
Total bilirubin $(\mu \mathrm{M} / \mathrm{L})$ & $0.66 \pm 0.22$ & $0.60 \pm 0.10$ & $0.59 \pm 0.16$ \\
Direct bilirubin $(\mu \mathrm{M} / \mathrm{L})$ & $1.10 \pm 0.05$ & $0.13 \pm 0.05$ & $0.19 \pm 0.16$ \\
Indirect bilirubin $(\mu \mathrm{M} / \mathrm{L})$ & $0.51 \pm 0.25$ & $0.44 \pm 0.17$ & $0.42 \pm 0.19$ \\
Blood urea nitrogen $(\mathrm{mmol} / \mathrm{L})$ & $9.31 \pm 1.02$ & $7.23 \pm 1.87^{*}$ & $7.15 \pm 0.47^{*}$ \\
Creatinine $(\mu \mathrm{M} / \mathrm{L})$ & $16.07 \pm 3.43$ & $16.08 \pm 1.87$ & $15.18 \pm 2.44$ \\
RBC $\left(10^{12} / \mathrm{L}\right)$ & $10.97 \pm 1.26$ & $11.39 \pm 1.48$ & $9.58 \pm 0.82$ \\
Hemoglobin $(\mathrm{g} / \mathrm{L})$ & $214.30 \pm 11.78$ & $203.00 \pm 11.15$ & $206.0 \pm 9.93$ \\
WBC $\left(10^{9} / \mathrm{L}\right)$ & $12.92 \pm 0.18$ & $11.69 \pm 1.30$ & $12.72 \pm 1.75$ \\
$\mathrm{PLT}\left(10^{9} / \mathrm{L}\right)$ & $673.00 \pm 120.80$ & $613.70 \pm 145.00$ & $670.80 \pm 150.20$ \\
\hline
\end{tabular}

${ }^{*} P<0.05$ vs. control

PZQ showed the same performance as thiacloprid treatment (Fig. 4c).

\section{Thiacloprid inhibits acetylcholinesterase activity and glucose absorption}

Previous studies have shown that the inhibition of parasite acetylcholinesterase activity can suppress the absorption of host-derived glucose [36]. Our study confirmed the presence of acetylcholinesterase in the E. multilocularis protoscoleces, metacestodes and germinal cells (Additional file 7: Table S3). After thiacloprid treatment, acetylcholinesterase activity in protoscoleces, metacestode vesicles and germinal cells was suppressed (Fig. 4d). Positive control BW284c51 also inhibited acetylcholinesterase activity. Glucose consumption in E. multilocularis protoscoleces and germinal cells was also measured. The viability of protoscoleces and germinal cells was not affected by thiacloprid treatment for $1 \mathrm{~h}$ (Additional file 8: Figure S5). Both the protoscoleces and germinal cells exposed to thiacloprid showed reduced uptake of 2-DG. These results indicate that thiacloprid has the effect of inhibiting glucose uptake in protoscoleces and germinal cells (Fig. 4e).

\section{Toxicity evaluation of thiacloprid in vivo}

Adverse reactions of a drug can greatly limit its clinical application. Here, we further analyzed the in vivo toxicity of thiacloprid. For this, BALB/c mice were treated with thiacloprid for 6 weeks. The levels of ALT, AST, TBIL, DBIL, IBIL, TP, ALB, ALP, CREA and BUN in serum and the levels of WBC, $\mathrm{Hb}$ and PLT in whole blood are shown in Table 1. There was no significant difference in the above biochemical and hematological parameters between the thiacloprid treated group and the control group. These tests showed that thiacloprid had no significant effect on liver and kidney function in mice. Furthermore, the liver and kidneys of mice were subjected to histopathological examination after HE staining (Fig. 5). The livers and kidneys of mice treated with thiacloprid did not show obvious histopathological changes or injury.

\section{Effect of thiacloprid against E. multilocularis metacestodes in vivo}

An in vivo experiment was performed to investigate the therapeutic effect of thiacloprid. After 6 weeks of treatment, each metacestode in mice presented with polycystic growth, and representative metacestodes are presented in Additional file 9: Figure S6 and Fig. 6a. The metacestode weight data was not normally distributed according to Shapiro-Wilk test $(W=0.787 ; P=0.000)$. Kruskal-Wallis analysis indicated a significant reduction of the wet weights of the metacestodes in the Thia15 group $(1.63 \pm 0.62 \mathrm{~g})$, Thia30 group $(1.63 \pm 0.61 \mathrm{~g})$ and ABZ group $(1.85 \pm 0.94 \mathrm{~g})$ compared with the control group $(6.49 \pm 1.18$ g) (Fig. 6b). Thiacloprid treatment seemed to be more effective than ABZ, as there was no significant difference in the weight of their metacestodes. Thiacloprid also did not show dose-dependent tolerance. For pathological observation, the center of the lesions in the respective group presented caseous necrosis (Additional file 10: Figure S7). Considerable vacuoles could be observed in the metacestode after treatment 


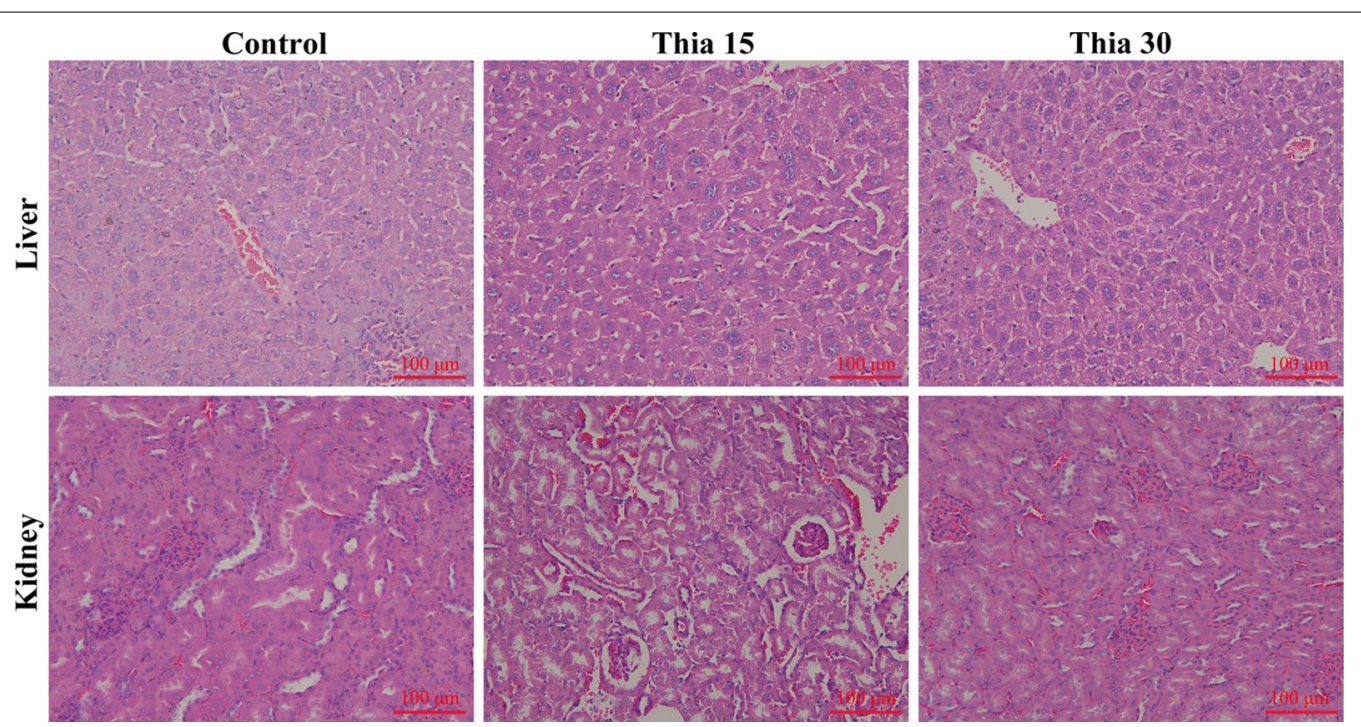

Fig. 5 Histopathological examination of liver and kidneys in thiacloprid-treated mice. Control tissues and thiacloprid-treated tissues were observed microscopically. Scale bar $=100 \mu \mathrm{m}$

with thiacloprid (Fig. 6c). However, germinal cells could still be observed in the ABZ group and untreated group (Fig. 6c). In addition, in the thiacloprid-treated group, only a few laminated layers were observed by PAS staining (Fig. 6d). Since spleen enlargement was observed after thiacloprid treatment, changes in $\mathrm{T}$ lymphocyte subsets and cytokines were further investigated.

\section{Thiacloprid regulates lymphocyte subset}

In the isolation of metacestodes in mice, we observed enlarged spleens, and the spleen index of mice increased after treatment with thiacloprid (Fig. 7a). Since cellular immunity is critical to $\mathrm{AE}$, we further analyzed the effect of thiacloprid on $\mathrm{T}$ lymphocyte subsets in the metacestodes and spleen. According to the analysis of blood cells, the percentage of lymphocytes increased, and the percentage of eosinophils and neutrophils was downregulated after treatment with thiacloprid (Additional file 11: Table S4). Furthermore, after treatment with thiacloprid, $\mathrm{CD}^{+} \mathrm{T}$ lymphocytes increased and $\mathrm{CD}^{+} \mathrm{T}$ lymphocytes decreased as compared with the untreated group in the metacestodes and spleen (Fig. 7b, c). Moreover, the infiltration of neutrophils in the metacestodes was reduced, while there were more infiltration of plasma cells, lymphocytes and macrophages (Additional file 12: Figure S8).

\section{Thiacloprid enhances the level of anti-AE cytokines in serum}

To further assess the immune effects induced by thiacloprid, cytokine levels were detected by ELISA. Echinococcus multilocularis metacestode infection caused the expression of IL-2, IL-4 and IL-10 to be downregulated, and the expression of IgE to be upregulated. Thiacloprid treatment upregulated the expression of IL-2, IL-4 and IL-10 and downregulated the expression of IgE compared with the untreated group (Fig. 7d). ABZ led to consistent variations. Moreover, the expression of IL-2, IL-4 and IL-10 in microcyst fluid was upregulated after thiacloprid treatment (Fig. 7e).

\section{Collagen deposition in the host-lesion microenvironment}

TEM was used to observe the ultrastructural changes of the host-lesion microenvironment (Fig. 8a). Abundant mitochondria, endoplasmic reticulum and ribosomes could be seen in the untreated group, and rough endoplasmic reticulum expanded obviously. In the ABZ

\footnotetext{
(See figure on next page.)

Fig. 6 In vivo activity of thiacloprid against E. multilocularis metacestodes. Two weeks after infection of BALB/c mice with metacestode tissues, the mice received the intragastric administration of thiacloprid for 6 weeks. The positive control was $100 \mathrm{mg} / \mathrm{kg}$ ABZ. a The images of metacestodes resected from different treatment groups. b Parasite weight in different treatment groups. The data are presented as mean \pm SD from seven independent experiments. c HE staining of E. multilocularis metacestodes from different treatment groups. Scale bar = $100 \mu \mathrm{m}$. LL: laminated layer; FT: fibrous tissue; Va: vacuole. $\mathbf{d}$ Laminated layer PAS staining. The section shows PAS-positive laminated layer of E. multilocularis metacestodes. Scale bar $=200 \mu \mathrm{m}$
} 

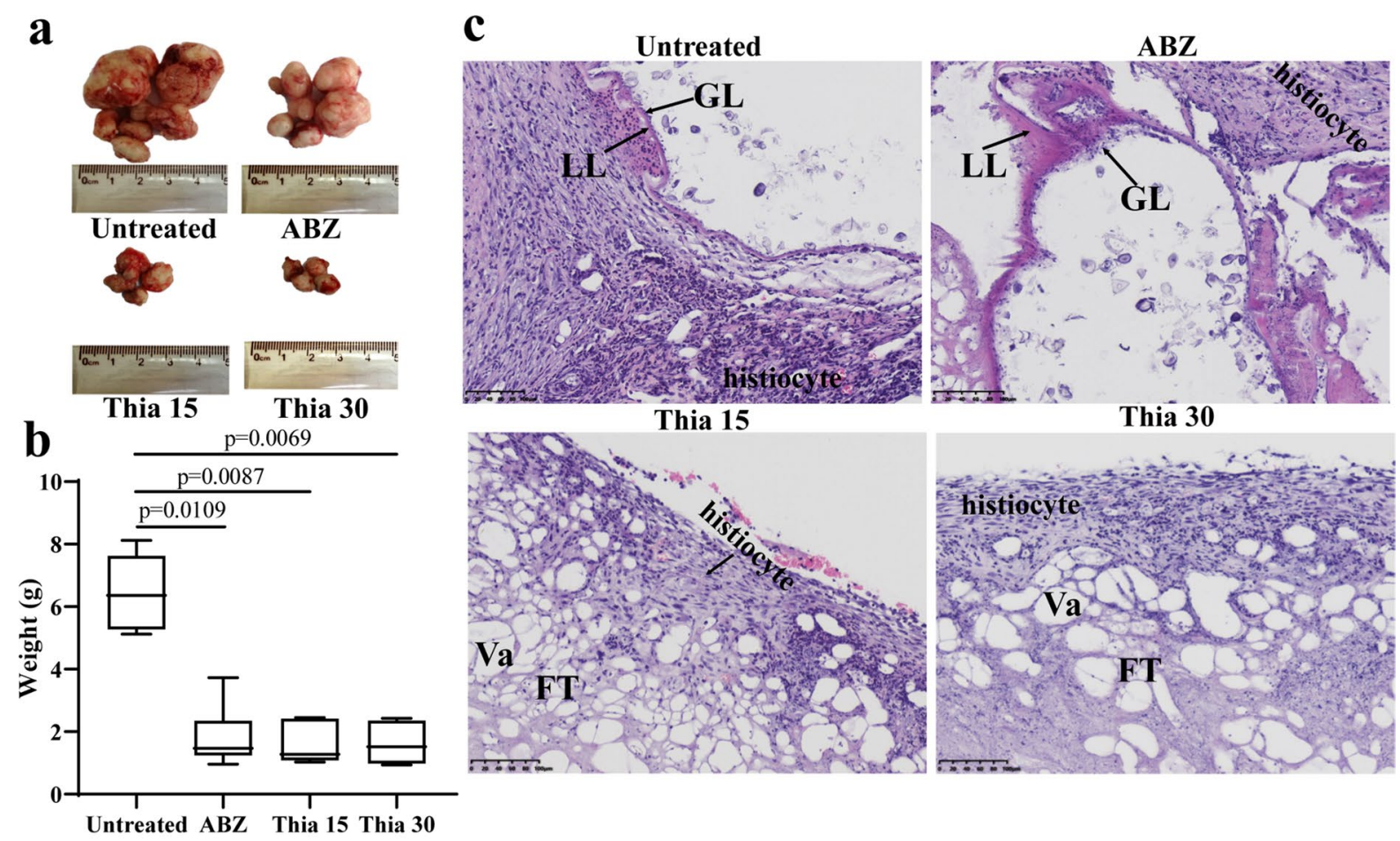

Thiä 30

d

Untreated

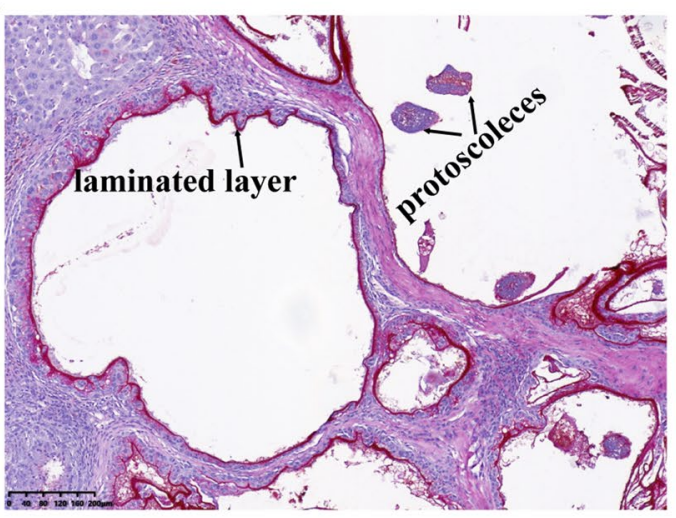

Thia15

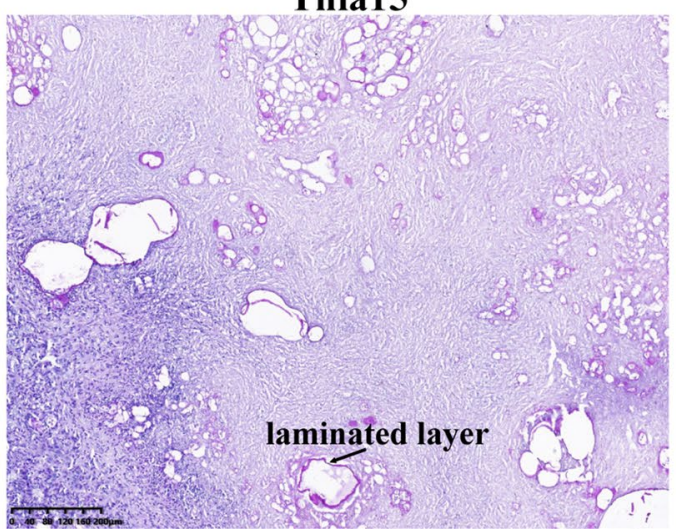

ABZ

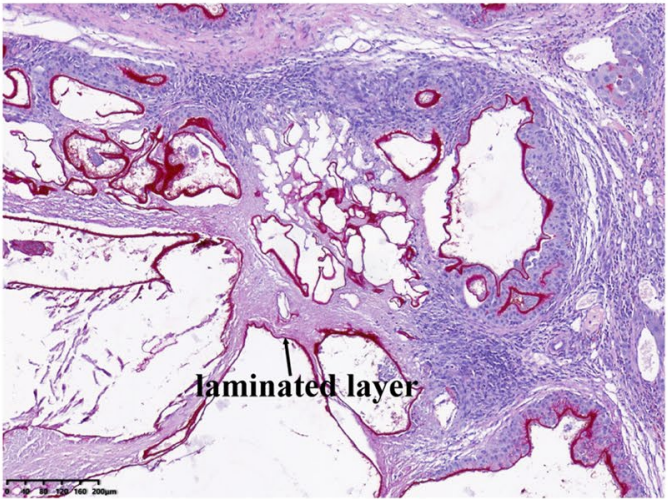

Thia30

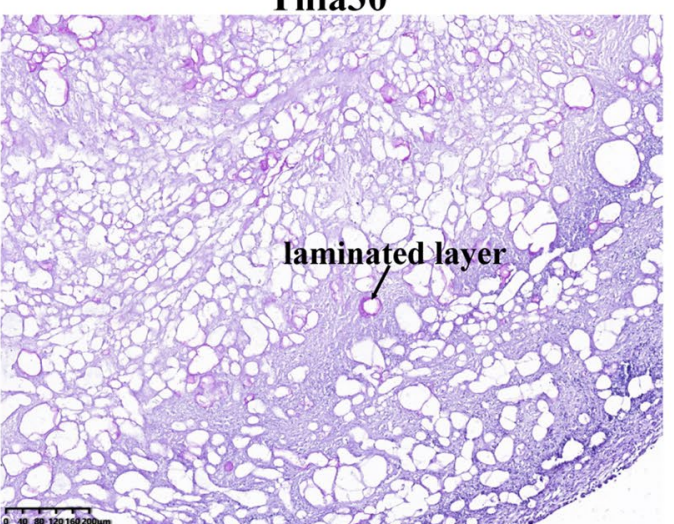

Fig. 6 (See legend on previous page.) 


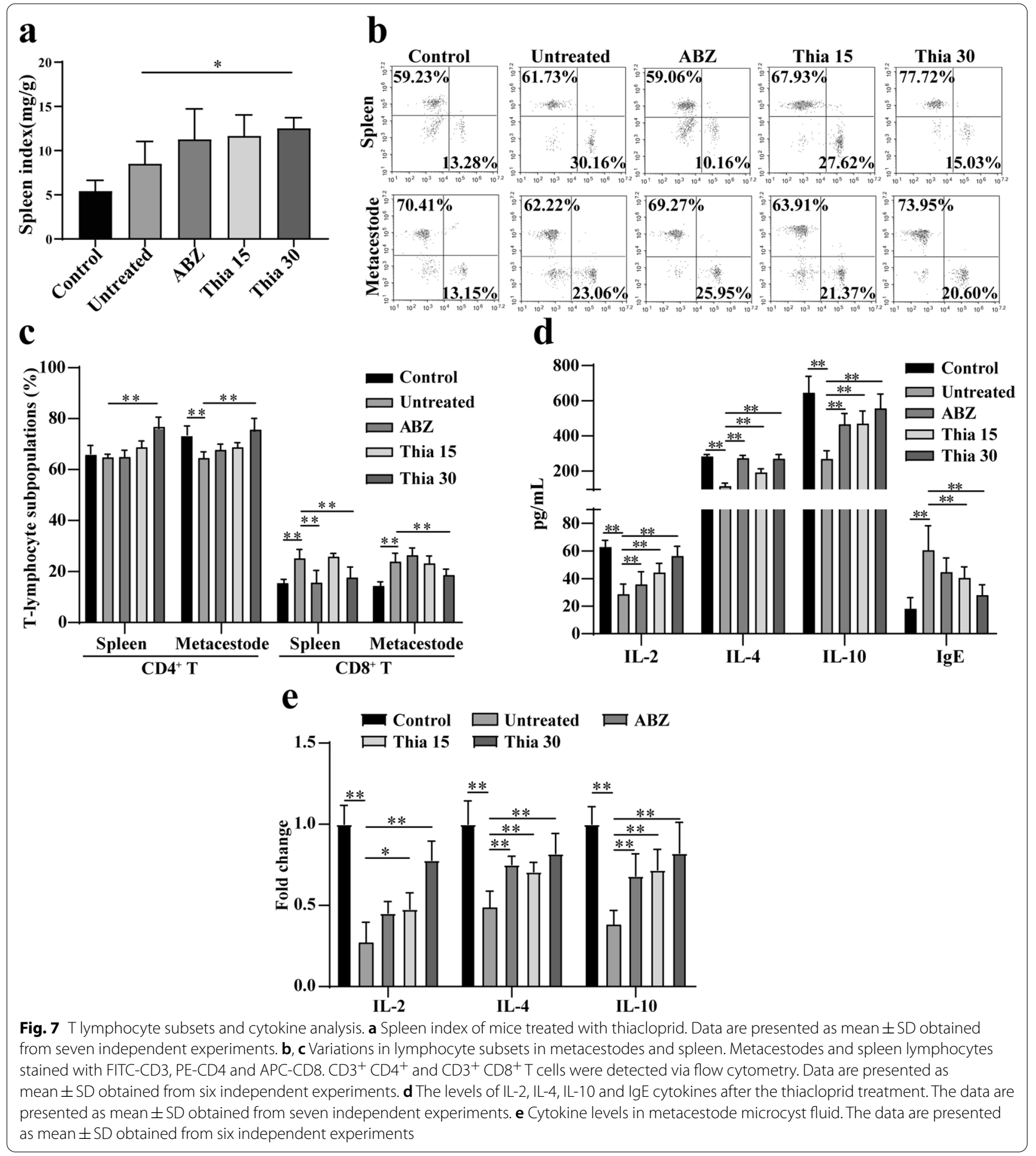

group, autophagosomes appeared; there were many vacuoles in the cytoplasm; collagen fibers were deposited in the extracellular matrix. In the microenvironment of the Thia15 group, mitochondrial cristae ruptured or disappeared and autophagosomes appeared, and a large number of collagen fibers were deposited in the intercellular substance. In the microenvironment of the Thia30 group, cell necrosis was observed. Mitochondrial cristae disappeared; many vacuoles were found in the cytoplasm, and abundant collagen fibres were deposited in the intercellular substance. Sirius red staining further confirmed collagen fiber deposition in the host-lesion 


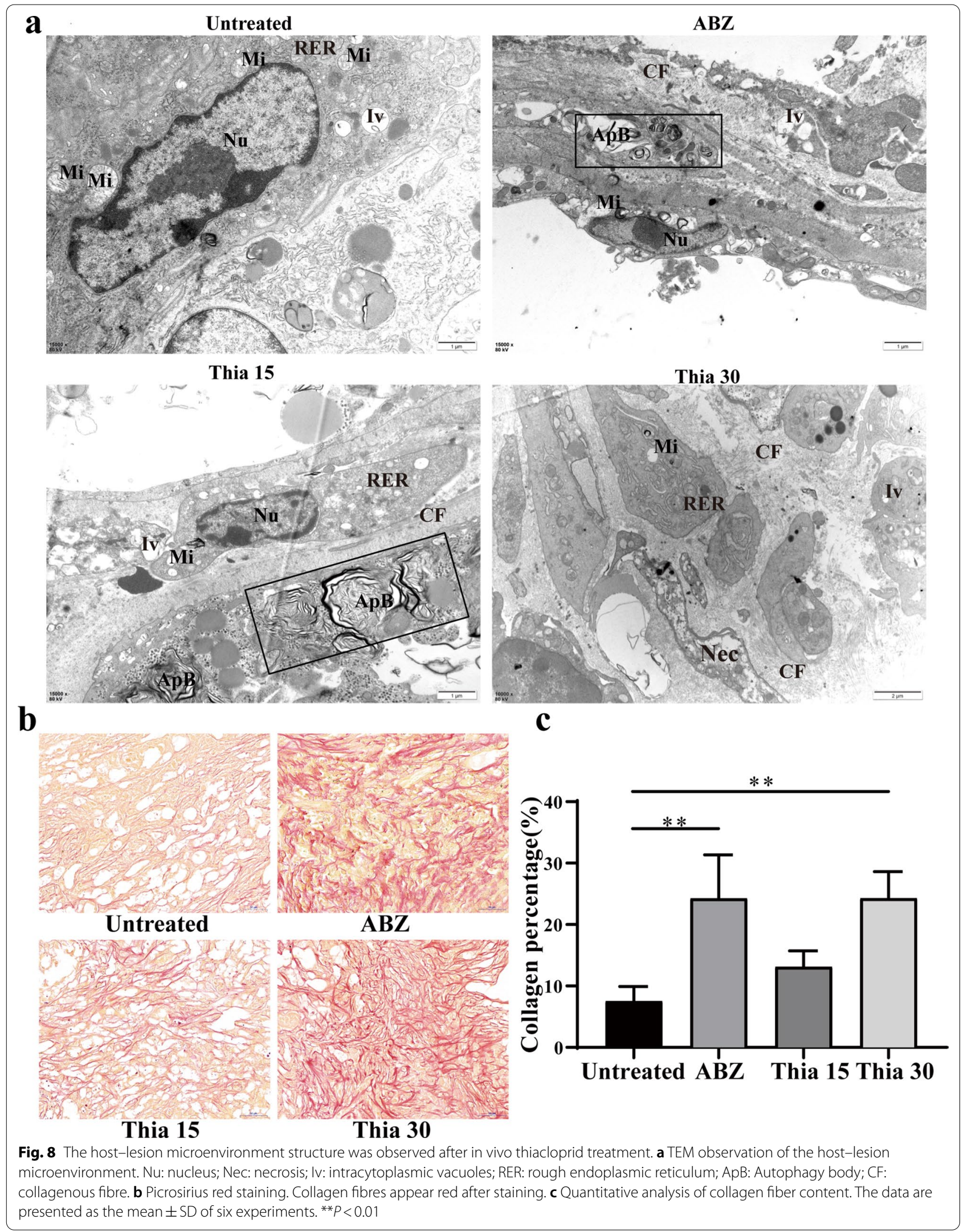


(See figure on next page.)

Fig. 9 Thiacloprid inhibits MMP activity in the host-lesion microenvironment. a Quantitative PCR analysis of collagen I and III expression in the host-lesion microenvironment. The data are presented as the mean \pm SD of six experiments. b Western blotting was used to detect the protein expression of collagen I and III. c Quantitative analysis of collagen I and III protein levels. The data are presented as the mean \pm SD of five experiments. d Quantitative PCR analysis of MMP expression in the host-lesion microenvironment. The data are presented as the mean \pm SD of six experiments. e Western blotting was used to detect the protein expression of MMPs. $\mathbf{f}$ Quantitative analysis of MMP protein levels. The data are presented as the mean \pm SD of five experiments. ${ }^{*} P<0.05$ and ${ }^{*} P<0.01$

microenvironment after thiacloprid or PZQ treatment (Fig. 8b, c). The results show that thiacloprid or ABZ can promote autophagy in the host-host microenvironment, especially collagen fiber deposition.

\section{Thiacloprid inhibits the activity of matrix metalloproteinases (MMPs)}

MMPs are the main factors leading to collagen degradation; thus, we further studied the effect of thiacloprid on MMP production. After thialoprid or ABZ treatment, mRNA and protein expression levels of collagen I and III in the host-lesion microenvironment were increased $($ Fig. 9a-c). We then evaluated the mRNA expression levels of related MMPs in the microenvironment (Fig. 9d). After thiacloprid or ABZ treatment, the mRNA expression of MMP1, MMP3, MMP9 and MMP13 in the microenvironment was significantly inhibited. In addition, the protein expression levels of MMP1, MMP3, MMP9 and MMP13 were decreased after thiacloprid or ABZ treatment (Fig. 9e, f). The results demonstrate that thiacloprid can reduce the breakdown of extracellular collagen by inhibiting the expression of MMPs.

\section{Discussion}

Echinococcosis remains a major public health problem worldwide, seriously affecting the health of people in pastoral areas and causing substantial social problems and economic losses to animal husbandry [37]. Current chemotherapy regimens rely on benzimidazole treatment. The role of drug therapy pre- and post-AE surgery is irreplaceable. However, it can only inhibit the growth and dispersion of metacestodes, but cannot kill the parasite [38]. Therefore, new drugs or lead compounds are needed.

Since the initial identification of members of the $E$. multilocularis nAchR family, few studies have explored the effects of echinococcus nAchR-targeting drugs on parasite growth and development [39]. In the present study, we screened the neonicotinoids in vitro for active compounds against $E$. multilocularis metacestodes using PGI assays. The glycolytic enzyme PGI is a moonlighting protein that has been shown to stimulate the proliferation of both parasite germinal cells and mammalian endothelial cells [40]. In recent years, in vitro models of E. multilocularis have been able to produce large-scale metacestode vesicles in favor of drug screening. Meanwhile, the fact that PGI is a prominent component of the vesicle fluid has been exploited for the development of the PGI screening assay, which enables quantitative screening for drugs that impair the structural integrity of metacestodes in such a way that vesicle fluid is released into the medium supernatant [29]. All the neonicotinoids acted on metacestode vesicles at a dose of $20 \mu \mathrm{M}$, but only thiacloprid showed activity. The $\mathrm{EC}_{50} / \mathrm{IC}_{50}$ value of thiacloprid anti-metacestode vesicle and germinal cell activity was $4.54 \pm 1.10 \mu \mathrm{M}$ and $2.89 \pm 0.34 \mu \mathrm{M}$, which was significantly lower than the toxicity of thiacloprid to mammalian cells. This suggests that thiacloprid has potential therapeutic effects for further analysis. We observed by TEM that thiacloprid caused the germinal layer structure to be destroyed or the germinal layer separated from tegument. Although treatment with $5 \mu \mathrm{M}$ thiacloprid for 4 days only resulted in the death of $47.33 \pm 4.04 \%$ protoscoleces, the survival of germinal cells was found to be less than $40 \%$ at $5 \mu \mathrm{M}$. These results indicated that germinal cells were more sensitive to thiacloprid than protoscoleces. We also demonstrated that thiacloprid can affect protoscolex acetylcholinesterase activity. It has been reported that neonicotinoids inhibit the activity of acetylcholinesterase in worm [41]. With parasite acetylcholinesterase activity inhibited, the breakdown of acetylcholine will reduce the absorption of host-derived glucose [36]. Our results demonstrated that thiacloprid treatment reduced glucose absorption. Therefore, thiacloprid may play a parasitic role by inhibiting the glucose absorption of the protoscoleces.

The wet weight of metacestodes decreased significantly after thiacloprid treatment in mice, demonstrating an identical effect to albendazole [42]. The germinal layer was obviously destroyed after thiacloprid treatment. Thiacloprid caused a decrease in the number of eosinophils and neutrophils in the blood. Eosinophils are recognized as end-stage cells involved in protecting the host against parasitic infections [43]. Once the parasite dies or escapes host immunity, inflammation is mitigated [44]. No obvious eosinophil deposition was identified in the metacestode, whereas there was considerable lymphocyte, plasma cell and macrophage aggregation. The effect of albendazole on eosinophils in parasite infection remains controversial $[42,45]$. Plasma cells are capable 


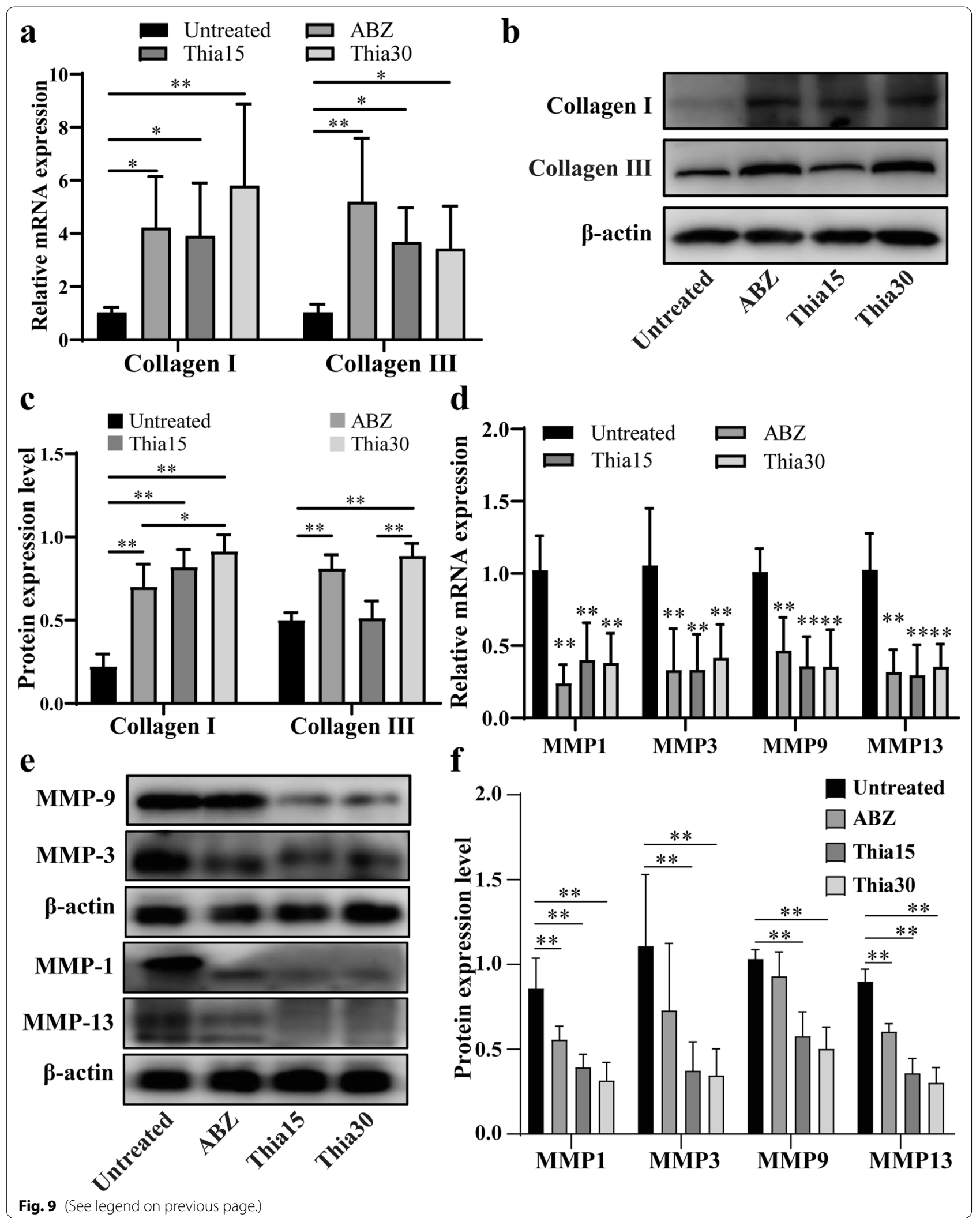


of secreting immunoglobulin and penetrating the metacestode wall to exert an anti-echinococcosis effect. White blood cells are involved in cell differentiation, inflammatory response expansion, and even innate and adaptive immune regulation [46].

Anti-echinococcosis immunity is dominated by $\mathrm{T}$ cellmediated cellular immune responses [47]. In the state of chronic infection, there are numerous activated $\mathrm{CD} 8^{+} \mathrm{T}$ lymphocytes in the peripheral blood [48], and $\mathrm{CD} 8^{+} \mathrm{T}$ lymphocytes cause immunosuppression in $\mathrm{AE}$ [49]. $\mathrm{CD} 4^{+}$ $\mathrm{T}$ lymphocyte-mediated cellular immunity is required to resist E. multilocularis infection [50]. The use of CD4deficient and CD8-deficient mice proves that $\mathrm{CD} 4^{+} \mathrm{T}$ lymphocyte-mediated cellular immunity is necessary to resist E. multilocularis infection [50]. Thiacloprid increased the ratio of $\mathrm{CD}^{+}{ }^{+} \mathrm{T}$ cells in metacestodes and spleen, while downregulating the ratio of $\mathrm{CD}^{+} \mathrm{T}$ cells, which resulted in an increase in the ratio of $\mathrm{CD}^{+} / \mathrm{CD}^{+}$ $\mathrm{T}$ lymphocytes. This demonstrated that the anti-echinococcosis effect of thiacloprid in vivo may also enhance the cellular immune response. Thiacloprid reversed the immunosuppression after $E$. multilocularis metacestode infection. However, there is an imbalance between the activation of Th1 and Th2 cell immune response during the occurrence of echinococcosis, resulting in differences in cytokine secretion. In the host immune response to parasite infection, IL-4 is crucial to the protective immunity against extracellular parasite infection [51, 52]. IL-2 is recorded as a critical cytokine in positive immune regulation [53]. Thiacloprid led to elevated expression of IL-2, IL-4, IL-10 and downregulated the expression of IgE in mice with secondary infection of $\mathrm{AE}$, and $\mathrm{ABZ}$ exerted a consistent effect. The application of thiacloprid is conducive to mitigating the immunosuppression of E. multilocularis metacestode infection. However, as indicated by excessive IL-10, the immune function of T-lymphocytes is in an inhibited state, which is conducive to the survival of parasites [54]. Thus it could be speculated that IL-10 may play an anti-echinococcosis role by downregulating VEGF expression and inhibiting angiogenesis in the metacestodes [55]. Although certain insights into immunization against echinococcosis have been gained, many immune mechanisms remain unclear, which should be researched in greater depth.

The most prominent feature of the host-lesion microenvironment is the effective accumulation of ECM, the main component of which is collagen $[4,6]$. Our study confirmed that the deposition of collagen I and III in the host-lesion microenvironment increased after treatment with thiacloprid, which may be beneficial in promoting fibrosis and calcification of metacestodes. MMPs are the main enzymes for collagen degradation in ECM [56]. To evaluate whether the increase in collagen is accompanied by changes in MMPs, we detected MMPs related to the degradation of type I and III collagen and found that thiacloprid induced a decrease in MMP-1, MMP-3, MMP-9 and MMP-13 protein expression levels in the host-lesion microenvironment. MMPs are a group of endogenous proteases that rely on zinc and calcium to catalyze their activity. They are secreted in the extracellular space and degrade all molecular components of ECM [57]. Therefore, our results demonstrated that the promotion of collagen production by thiacloprid is probably related to the weakening of MMP activity.

The advantage of thiacloprid over nicotine lies in its lower toxicity. In fact, thiacloprid has been widely adopted to control surface parasites in cats and dogs [58]. Thiacloprid shows low toxicity to mammalian cells. Previous studies found that thiacloprid treatment with more than $108 \mathrm{mg} / \mathrm{kg}$ induced obvious hepatocellular hypertrophy and cytoplasm degeneration in mice [59]. Moreover, thiacloprid had no significant biochemical or hematological effects, and had no effect on liver or kidney morphology. This indicates that thiacloprid at concentrations below at least $30 \mathrm{mg} / \mathrm{kg}$ does not cause significant in vivo toxicity. Previous studies have shown that $22.5 \mathrm{mg} / \mathrm{kg}$ thiacloprid can cause hepatocellular necrosis and hydropic degeneration [35], and the reason for the inconsistent results may be related to the fact that the hypoxic environment in which we live reduces the absorption of drugs. Over the past few years, neonicotinoids have been found to be promising lead compounds for developing reversible cholinesterase inhibitors against Alzheimer's disease [60]. However, although thiacloprid has low toxicity, high doses of thiacloprid still impact bone marrow erythrocytes and chromosomes to a certain extent [61]. In addition, neonicotinoids do not easily cross the blood-brain barrier, so thiacloprid in its current form is not suitable for the treatment of cerebral echinococcosis.

\section{Conclusions}

Thiacloprid was identified from seven neonicotinoids with potent in vitro activity against E. multilocularis metacestodes. In addition, we demonstrated that thiacloprid inhibits metacestode and germinal cells acetylcholinesterase activity. Thiacloprid inhibited metacestode growth in vivo. Thiacloprid enhanced the activity of $\mathrm{CD}^{+} \mathrm{T}$ lymphocytes, promoted the expression of anti-echinococcosis related cytokines in serum, and promoted host-lesion microenvironment collagen deposition. This study underlines the potential for the development of thiacloprid as an anti-E. multilocularis drug. 


\begin{abstract}
Abbreviations
AE: Alveolar echinococcosis; E. multilocularis: Echinococcus multilocularis; PGI: Phosphoglucose isomerase; HFF: Human foreskin fibroblast; RH: Reuber rat hepatoma; 2-DG: 2-Deoxyglucose; ELISA: Enzyme-linked immunosorbent assay; IL: Interleukin; MMP: Matrix metalloproteinase; ABZ: Albendazole; MBZ Mebendazole; nAchRs: Nicotinic acetylcholine receptors; DMEM: Dulbecco's modified Eagle medium; FBS: Fetal bovine serum; DMSO: Dimethyl sulfoxide; GAPDH: Glyceraldehyde-3-phosphate dehydrogenase; RT-PCR: Reverse transcription polymerase chain reaction; $\mathrm{CDNA}$ : Complementary DNA; PZQ: Praziquantel; $\mathrm{EC}_{50}$ : Median effective concentration; $\mathrm{IC}_{50}$ : Median inhibitory concentration; PBS: Phosphate-buffered saline; ABZSO: Albendazole sulfoxide; HE: Hematoxylin-eosin; PAS: Periodic acid-Schiff; OD: Optical density; lgE: Immunoglobulin E; SEM: Scanning electron microscopy; TEM: Transmission electron microscopy; RT-qPCR: Reverse transcription quantitative polymerase chain reaction; mRNA: Messenger RNA; SDS-PAGE: Sodium dodecyl sulfate polyacrylamide gel electrophoresis; TBST:Tris-buffered saline Tween 20.
\end{abstract}

\section{Supplementary Information}

The online version contains supplementary material available at https://doi. org/10.1186/s13071-021-04952-7.

Additional file 1: Figure S1. Chemical structure and functional groups of neonicotinoids. a Chemical structure of neonicotinoids. Chemical struc ture obtained from PubChem database. $\mathbf{b}$ Functional group information of neonicotinoids.

Additional file 2: Figure S2. Screening of the neonicotinoids on E. multilocularis metacestodes in vitro. Confirmation of active drugs by testing at $20 \mu \mathrm{M}$ in triplicates. Relative PGI release as assessed by PGI-assay is shown. $100 \%$ PGI release was defined as the release upon treatment with the positive control $0.1 \%$ Triton-100. Drugs were considered as active if they exceeded $20 \%$ relative $P G I$ release (dashed line).

Additional file 3: Figure S3. Isolation of metacestodes from Mongolian gerbil. The black arrows show the protoscoleces.

Additional file 4: Table S1. Specific primer sequences.

Additional file 5: Table S2. Antibody information.

Additional file 6: Figure S4. Metacestode vesicle (a) and germinal cells (b) cultured in vitro.

Additional file 7: Table S3. Echinococcus multilocularis cholinesterase activity.

Additional file 8: Figure S5. The cell viability of protoscoleces and germinal cells treated with thiacloprid for $1 \mathrm{~h}$. a Survival of protoscoleces after treatment with thiacloprid. To evaluate the survival of protoscoleces, $0.1 \%$ eosin staining exclusion method was used. b Mitochondrial probe labeling of living cells.

Additional file 9: Figure S6. Metacestode in the abdominal cavity of mice. The black arrows showed metacestodes.

Additional file 10: Figure S7. The center of the metacestodes showed caseous necrosis. HE staining showed caseous necrosis in the centre of the metacestode (scale bar $=400 \mu \mathrm{m}$ ). There is no structural granular and no residual shadow of the original tissue structure.

Additional file 11: Table S4. Blood cell analysis of mice infected with $E$. multilocularis treated with thiacloprid $(n=6)$.

Additional file 12: Figure S8. Immune cell infiltration in host tissue surrounding metacestode. After thiacloprid treatment, infiltration of neutrophils decreased (a) and infiltration of plasma cells, lymphocytes and macrophages increased in host tissue surrounding metacestode (b). The red arrow shows the neutrophils, the black arrow shows the lymphocytes, the green arrow shows the eosinophils, the blue arrow shows the plasma cells, and the yellow arrow shows the macrophages.

\section{Acknowledgements}

We thank Dr. Mingquan Pang in the Department of Hepatobiliary and Pancreatic Surgery, Qinghai University Affiliated Hospital, for his help in the construction of the secondary AE model.

\section{Authors' contributions}

CCL conceived of the study, carried out all the experiments and drafted the manuscript. HNF guided the construction of the secondary AE model. JM contributed to flow cytometry. LM and RLG participated in the design and supervision of the study and helped to revise the manuscript. All authors have read and approved the final manuscript.

\section{Funding}

This study was financed in part by the Province Natural Science Foundation of Qinghai (2020-ZJ-Y01); the National Key Research and Development Projects (2017YFC0909900); and the Kunlun Innovative and Entrepreneurial Talent Program of Qinghai Province (2020).

\section{Availability of data and materials}

Data supporting the conclusions of this article are included within the article and its additional files.

\section{Declarations}

Ethics approval and consent to participate

Animal procedures were approved by the Institutional Review Board of the Medical College of Qinghai University (IACUC-201905010005) and the Qinghai University Affiliated Hospital (AF-RHEC-0018-01).

\section{Consent for publication}

Not applicable.

\section{Competing interests}

The authors declare that they have no competing interests.

\section{Author details}

${ }^{1}$ Research Center for High Altitude Medicine, Qinghai University, Xining 810001, Qinghai, China. ${ }^{2}$ Qinghai University Affiliated Hospital, Xining 810001, Qinghai, China. ${ }^{3}$ Qinghai Key Laboratory for Echinococcosis, Xining 810001, Qinghai, China. ${ }^{4}$ Qinghai Key Laboratory of Science and Technology for High Altitude Medicine, Xining 810001, Qinghai, China. ${ }^{5}$ QinghaiUtah Joint Research Key Lab for High Altitude Medicine, Xining 810001, Qinghai, China.

Received: 16 March 2021 Accepted: 12 August 2021

Published online: 06 September 2021

\section{References}

1. Kristianova H, Kolarova L, Krska Z, Chrz K, Dytrych P. Surgical treatment of alveolar echinococcosis: a single centre experience and systematic review of the literature. Rozhl Chir. 2019;98(4):167-73.

2. Laurimäe T, Kinkar L, Moks E, Romig T, Omer RA, Casulli A, et al. Molecular phylogeny based on six nuclear genes suggests that Echinococcus granulosus sensu lato genotypes $\mathrm{G} 6 / \mathrm{G} 7$ and G8/G10 can be regarded as two distinct species. Parasitology. 2018;145(14):1929-37.

3. Wen H, Vuitton L, Tuxun T, Li J, Vuitton DA, Zhang W, et al. Echinococcosis: advances in the 21st Century. Clin Microbiol Rev. 2019;32(2):e00075-e118.

4. Díaz Á, Sagasti C, Casaravilla C. Granulomatous responses in larval taeniid infections. Parasite Immunol. 2018;40(5):e12523.

5. Ito T, Connett JM, Kunkel SL, Matsukawa A. The linkage of innate and adaptive immune response during granulomatous development. Front Immunol. 2013:4:10.

6. Almadani N, Almutairi B, Alassiri AH. Primary subcutaneous hydatid cyst with palisading granulomatous reaction. Case Rep Pathol. 2013;2013:126541.

7. Caire Nail L, Rodríguez Reimundes E, Weibel Galluzzo C, Lebowitz D, Lucile Ibrahim Y, Alexander Lobrinus J, et al. Disseminated alveolar 
echinococcosis resembling metastatic malignancy: a case report. J Med Case Rep. 2017;11(1):113.

8. Siles-Lucas M, Casulli A, Cirilli R, Carmena D. Progress in the pharmacological treatment of human cystic and alveolar echinococcosis: compounds and therapeutic targets. PLoS Negl Trop Dis. 2018;12(4):e0006422.

9. Vuitton DA, Azizi A, Richou C, Vuitton L, Blagosklonov O, Delabrousse E, et al. Current interventional strategy for the treatment of hepatic alveolar echinococcosis. Expert Rev Anti Infect Ther. 2016;14(12):1179-94.

10. Lundström-Stadelmann B, Rufener R, Hemphill A. Drug repurposing applied: activity of the anti-malarial mefloquine against Echinococcus multilocularis. Int J Parasitol Drugs Drug Resist. 2020;13:121-9.

11. Grüner B, Kern P, Mayer B, et al. Comprehensive diagnosis and treatment of alveolar echinococcosis: a single-center, long-term observational study of 312 patients in Germany. GMS Infect Dis. 2017;5:Doc01.

12. Lundström-Stadelmann B, Rufener R, Ritler $D$, Zurbriggen $R$, Hemphill A. The importance of being parasiticidal... an update on drug development for the treatment of alveolar echinococcosis. Food Waterborne Parasitol. 2019;15:e00040.

13. Rufener R, Dick L, D'Ascoli L, Ritler D, Hizem A, Wells NCT, et al. Repurposing of an old drug: in vitro and in vivo efficacies of buparvaquone against Echinococcus multilocularis. Int J Parasitol Drugs Drug Resist. 2018:8(3):440-50.

14. Tomizawa M, Casida JE. Molecular recognition of neonicotinoid insecticides: the determinants of life or death. Acc Chem Res. 2009:42(2):260-9.

15. Matsuda K, Ihara M, Sattelle DB. Neonicotinoid insecticides: molecular targets, resistance, and toxicity. Annu Rev Pharmacol Toxicol. 2020:60:241-55

16. Tufi S, Wassenaar PN, Osorio V, de Boer J, Leonards PE, Lamoree MH. Pesticide mixture toxicity in surface water extracts in snails (Lymnaea stagnalis) by an in vitro acetylcholinesterase inhibition assay and metabolomics. Environ Sci Technol. 2016:50(7):3937-44.

17. Kimura-Kuroda J, Nishito Y, Yanagisawa H, Kuroda Y, Komuta Y, Kawano $\mathrm{H}$, et al. Neonicotinoid insecticides alter the gene expression profile of neuron-enriched cultures from neonatal rat cerebellum. Int J Environ Res Public Health. 2016;13(10):987.

18. Tomizawa M, Casida JE. Selective toxicity of neonicotinoids attributable to specificity of insect and mammalian nicotinic receptors. Annu Rev Entomol. 2003:48:339-64.

19. Selvam V, Srinivasan S. Neonicotinoid poisoning and management. Indian J Crit Care Med. 2019;23(Suppl 4):S260-2.

20. Calderón-Segura ME, Gómez-Arroyo S, Villalobos-Pietrini R, MartínezValenzuela C, Carbajal-López Y, Calderón-Ezquerro MDC, et al. Evaluation of genotoxic and cytotoxic effects in human peripheral blood lymphocytes exposed in vitro to neonicotinoid insecticides news. J Toxicol. 2012;2012:612647.

21. Schwabe CW, Koussa M, Acra AN. Host-parasite relationships in echinococcosis - IV. Acetylcholinesterase and permeability regulation in the hydatid cyst wall. Comp Biochem Physiol. 1961;2:161-72.

22. Koziol U, Krohne G, Brehm K. Anatomy and development of the larval nervous system in Echinococcus multilocularis. Front Zool. 2013;10(1):24.

23. Hu Y, Miller M, Zhang B, Nguyen TT, Nielsen MK, Aroian RV. In vivo and in vitro studies of Cry $5 \mathrm{~B}$ and nicotinic acetylcholine receptor agonist anthelmintics reveal a powerful and unique combination therapy against intestinal nematode parasites. PLoS Negl Trop Dis. 2018;12(5):e0006506.

24. Li L, Chen B, Yan H, Zhao Y, Lou Z, Li J, et al. Three-dimensional hepatocyte culture system for the study of Echinococcus multilocularis larval development. PLoS Negl Trop Dis. 2018;12(3):e0006309.

25. Spiliotis M, Tappe D, Sesterhenn L, Brehm K. Long-term in vitro cultivation of Echinococcus multilocularis metacestodes under axenic conditions. Parasitol Res. 2004;92(5):430-2.

26. Stadelmann B, Scholl S, Müller J, Hemphill A. Application of an in vitro drug screening assay based on the release of phosphoglucose isomerase to determine the structure-activity relationship of thiazolides against Echinococcus multilocularis metacestodes. J Antimicrob Chemother. 2010;65(3):512-9.

27. Nitta S, Hisasue M, Horiguchi Y, Yamada Y, Kikuchi K, Kubo T, et al. Threedimensional spheroid culture of canine hepatocyte-like cells derived from bone marrow mesenchymal stem cells. Regen Ther. 2020;15:210-5.

28. Stadelmann B, Aeschbacher D, Huber C, Spiliotis M, Müller J, Hemphill A. Profound activity of the anti-cancer drug bortezomib against
Echinococcus multilocularis metacestodes identifies the proteasome as a novel drug target for cestodes. PLoS Negl Trop Dis. 2014;8(12):e3352.

29. Stadelmann B, Rufener R, Aeschbacher D, Spiliotis M, Gottstein B, Hemphill A. Screening of the open source malaria box reveals an early lead compound for the treatment of alveolar echinococcosis. PLoS Negl Trop Dis. 2016;10(3):e0004535.

30. Spiliotis M, Lechner S, Tappe D, Scheller C, Krohne G, Brehm K. Transient transfection of Echinococcus multilocularis primary cells and complete in vitro regeneration of metacestode vesicles. Int J Parasitol. 2008;38(8-9):1025-39.

31. María AC, Celina EM. Efficacy of albendazole in combination with thymol against Echinococcus multilocularis protoscoleces and metacestodes. Acta Trop. 2014;140:61-7.

32. Giménez-Pardo C, Ros Moreno RM, De Armas-Serra C, RodríguezCaabeiro F. Presence of cholinesterases in Echinococcus granulosus protoscolices. Parasite. 2000;7(1):47-50.

33. Ellman GL, Courtney KD, Andres V Jr, Feather-stone RM. A new and rapid colorimetric determination of acetylcholinesterase activity. Biochem Pharmacol. 1961; 7:88-95.

34. Loos JA, Cumino AC. In vitro anti-echinococcal and metabolic effects of metformin involve activation of AMP-activated protein kinase in larval stages of Echinococcus granulosus. PLoS ONE. 2015;10(5):e0126009.

35. Şekeroğlu V, Atlı Şekeroğlu Z, Kefelioğlu H. Cytogenetic effects of commercial formulations of deltamethrin and/or thiacloprid on Wistar rat bone marrow cells. Environ Toxicol. 2013;28(9):524-31.

36. You H, Liu C, Du X, Nawaratna S, Rivera V, Harvie M, et al. Suppression of Schistosoma japonicum acetylcholinesterase affects parasite growth and development. Int J Mol Sci. 2018;19(8):2426.

37. Shi Y, Wan X, Wang Z, Li J, Jiang Z, Yang Y. First description of Echinococcus ortleppi infection in China. Parasit Vectors. 2019;12(1):398.

38. Hemphill A, Stadelmann B, Rufener R, Spiliotis M, Boubaker G, Müller J, et al. Treatment of echinococcosis: albendazole and mebendazolewhat else. Parasite. 2014;21:70.

39. Tsai IJ, Zarowiecki M, Holroyd N, Garciarrubio A, Sánchez-Flores A, Brooks $\mathrm{KL}$, et al. The genomes of four tapeworm species reveal adaptations to parasitism. Nature. 2013;496(7443):57-63.

40. Stadelmann B, Spiliotis M, Müller J, Scholl S, Müller N, Gottstein B, et al. Echinococcus multilocularis phosphoglucose isomerase (EmPGl): a glycolytic enzyme involved in metacestode growth and parasite-host cell interactions. Int J Parasitol. 2010:40(13):1563-74.

41. Győri J, Farkas A, Stolyar O, Székács A, Mörtl M, Vehovszky Á. Inhibitory effects of four neonicotinoid active ingredients on acetylcholine esterase activity. Acta Biol Hung. 2017;68(4):345-57.

42. Yuan M, Luo Y, Xin Q, Gao H, Zhang G, Jing T. Efficacy of osthole for Echinococcus granulosus in vitro and Echinococcus multilocularis in vivo. Vet Parasitol. 2016;226:38-43.

43. Jafari R, Sanei B, Baradaran A, Kolahdouzan M, Bagherpour B, Yousofi DH. Immunohistochemical observation of local inflammatory cell infiltration. in the host-tissue reaction site of human hydatid cysts. J Helminthol. 2019;93(3):277-85.

44. Ariyaratne A, Finney C. Eosinophils and macrophages within the Th2induced granuloma: balancing killing and healing in a tight space. Infect Immun 2019:87(10):e00127-e219.

45. de Ruiter K, Tahapary DL, Sartono E, Nutman TB, Smit J, Koenderman $L$, et al. The effect of helminths on granulocyte activation: a cluster-randomized placebo-controlled trial in Indonesia. J Infect Dis. 2019;219(9):1474-82.

46. Rothenberg ME, Hogan SP. The eosinophil. Annu Rev Immunol. 2006;24:147-74.

47. Allen JE, Maizels RM. Diversity and dialogue in immunity to helminths. Nat Rev Immunol. 2011;11(6):375-88.

48. Luo Y, Zhang G, Liu X, Yuan M, Gao Q, Gao H, et al. Therapeutic and immunoregulatory effects of water-soluble alkaloids E2-a from Sophora moorcroftian a seeds as a novel potential agent against echinococcosis in experimentally protoscolex-infected mice. Vet Res. 2018;49(1):100.

49. Kizaki T, Kobayashi S, Ogasawara K, Day NK, Good RA, Onoé K. Immune suppression induced by protoscoleces of Echinococcus multilocularis in mice. Evidence for the presence of CD8dull suppressor cells in spleens of mice intraperitoneally infected with E. multilocularis. J Immunol. 1991;147(5):1659-66. 
50. Dai WJ, Waldvogel A, Siles-Lucas M, Gottstein B. Echinococcus multilocularis proliferation in mice and respective parasite 14-3-3 gene expression is mainly controlled by an alphabeta CD4 T-cell-mediated immune response. Immunology. 2004;112(3):481-8.

51. Zhu J.T helper 2 (Th2) cell differentiation, type 2 innate lymphoid cell (ILC2) development and regulation of interleukin-4 (IL-4) and IL-13 production. Cytokine. 2015;75(1):14-24

52. Ma XM, Bao GSH, Wan JM, et al. Therapeutic effects of Sophora moorcroftiana alkaloids in combination with albendazole in mice experimentally infected with protoscolices of Echinococcus granulosus. Braz I Med Biol Res. 2007;40(10):1403-8.

53. Yang Y, Xiu F, Cai Z, Wang J, Wang Q, Fu Y, et al. Increased induction of antitumor response by exosomes derived from interleukin-2 gene-modified tumor cells. J Cancer Res Clin Oncol. 2007;133(6):389-99.

54. Moore KW, de Waal MR, Coffman RL, O'Garra A. Interleukin-10 and the interleukin-10 receptor. Annu Rev Immunol. 2001;19:683-765.

55. Tanikawa T, Wilke CM, Kryczek I, Chen GY, Kao J, Núñez G, et al. Interleukin-10 ablation promotes tumor development, growth, and metastasis. Cancer Res. 2012;72(2):420-9.

56. Jabłońska-Trypuć A, Matejczyk M, Rosochacki S. Matrix metalloproteinases (MMPs), the main extracellular matrix (ECM) enzymes in collagen degradation, as a target for anticancer drugs. J Enzyme Inhib Med Chem. 2016;31(Supp1):177-83.
57. Craig VJ, Zhang L, Hagood JS, Owen CA. Matrix metalloproteinases as therapeutic targets for idiopathic pulmonary fibrosis. Am J Respir Cell Mol Biol. 2015;53(5):585-600.

58. Faro LR, Oliveira IM, Durán R, Alfonso M. In vivo neurochemical characterization of clothianidin induced striatal dopamine release. Toxicology. 2012;302(2-3):197-202

59. Alarcan J, Waizenegger J, Solano M, Lichtenstein D, Claudia L, Peijnenburg A, et al. Hepatotoxicity of the pesticides imazalil, thiacloprid and clothianidin_-individual and mixture effects. Food Chem Toxicol. 2020;140:111306

60. Teralı K. An evaluation of neonicotinoids' potential to inhibit human cholinesterases: protein-ligand docking and interaction profiling studies. J Mol Graph Model. 2018;84:54-63.

61. Quagliariello V, Rossetti S, Cavaliere C, Palo RD, Lamantia E, Castaldon $L$, et al. Metabolic syndrome, endocrine disruptors and prostate cancer associations: biochemical and pathophysiological evidences. Oncotarget. 2017;8(18):30606-16.

\section{Publisher's Note}

Springer Nature remains neutral with regard to jurisdictional claims in published maps and institutional affiliations.
Ready to submit your research? Choose BMC and benefit from:

- fast, convenient online submission

- thorough peer review by experienced researchers in your field

- rapid publication on acceptance

- support for research data, including large and complex data types

- gold Open Access which fosters wider collaboration and increased citations

- maximum visibility for your research: over $100 \mathrm{M}$ website views per year

At BMC, research is always in progress.

Learn more biomedcentral.com/submissions 